\title{
1 A cellular and molecular atlas reveals the basis of chytrid development.
}

2

3 Davis Laundon ${ }^{1,2}$, Nathan Chrismas ${ }^{1}$, Kimberley Bird ${ }^{1}$, Seth Thomas ${ }^{1}$, Thomas

4 Mock $^{2}$, \& Michael Cunliffe $e^{1,3}$

5

$6 \quad{ }^{1}$ Marine Biological Association, The Laboratory, Citadel Hill, Plymouth, UK

$7{ }^{2}$ School of Environmental Sciences, University of East Anglia, Norwich, UK

${ }^{3}$ School of Biological and Marine Sciences, University of Plymouth, Plymouth, UK

9

Correspondence: Michael Cunliffe

Marine Biological Association,

E:micnli@mba.ac.uk 


\section{ABSTRACT}

The chytrids (phylum Chytridiomycota) are a major early-diverging fungal lineage of ecological and evolutionary importance. Despite their importance, many fundamental aspects of chytrid developmental and cell biology remain poorly understood. To address these knowledge gaps, we combined quantitative volume electron microscopy and comparative transcriptome profiling to create an 'atlas' of the cellular and molecular basis of the chytrid life cycle, using the model chytrid

Rhizoclosmatium globosum. From our developmental atlas, we show that zoospores exhibit a specialised biological repertoire dominated by inactive ribosome aggregates, and that lipid processing is complex and dynamic throughout the cell cycle. We demonstrate that the chytrid apophysis is a distinct subcellular structure characterised by high intracellular trafficking, providing evidence for division of labour in the chytrid cell plan, and show that zoosporogenesis includes 'animal like' amoeboid cell morphologies resulting from endocytotic cargo transport from the interstitial maternal cytoplasm. Taken together, our results reveal insights into chytrid developmental biology and provide a basis for future investigations into earlydiverging fungal cell biology.

\section{INTRODUCTION}

The chytrids (phylum Chytridiomycota) are an early-diverging and predominantly unicellular fungal lineage of ecological importance. For example, some chytrid species are the causative agents of the global amphibian panzootic (Fisher and Garner, 2020) and virulent crop pests (van de Vossenberg et al., 2019), whilst others are algal parasites and saprotrophs in marine and freshwater ecosystems (Frenken 
et al., 2017; Grossart et al., 2019; Klawonn et al., 2021). Chytrid zoospores contain large amounts of intracellular storage lipids that are consumed by grazing zooplankton, making them responsible for a significant form of trophic upgrading in aquatic ecosystems (Kagami et al., 2017, 2014, 2007; Rasconi et al., 2020). Chytrids are also important from an evolutionary perspective as they retain cellular traits from the last common ancestor of branching fungi (Fig. 1A) that are now absent in hyphal fungi (Berbee et al., 2017; Nagy et al., 2018), as well as traits from the common ancestor of animals and fungi in the Opisthokonta (Medina et al., 2016; Prostak et al., 2021). This makes chytrids powerful models to explore the origin and evolution of innovations in fungal cell biology and the wider eukaryotic tree of life. To help fully appreciate chytrids in terms of their ecological and evolutionary contexts, it is necessary to resolve their core cell biology (Laundon and Cunliffe, 2021).

Central to chytrid cell biology is their distinctive dimorphic life cycle, consisting of a motile free-swimming uniflagellate zoospore that transforms into a sessile walled thallus with anucleate attaching and feeding rhizoids (Fig. 1B) (Laundon et al., 2020; Medina et al., 2019). The cell body component of the thallus develops into the zoosporangium from which the next generation of zoospores are produced (Fig. 1B). Any biological life cycle inherently represents a temporal progression, yet the chytrid life cycle can be categorised into four distinctive contiguous life stages (Berger et al., 2005). The first stage is the motile 'zoospore' which lacks a cell wall, does not feed, and colonises substrates or hosts. The second stage is the sessile 'germling' which develops immediately after zoospore settlement following flagellar retraction (or sometimes detachment), cell wall production (encystment), and initiation of rhizoid growth from an initial germ tube. The third stage is the vegetative 'immature thallus' which is associated with the highest levels of rhizoid development and overall 
cellular growth (Laundon et al., 2020). The cell plan of the immature thallus can be divided into three parts (Fig. 1B): the cell body which is ultimately destined for reproduction (zoosporogenesis), the rhizoid for attachment and feeding, and (in some chytrid species) a bulbous swelling between the cell body and rhizoid termed the 'apophysis', the function of which is currently poorly understood (Laundon and Cunliffe, 2021). The final life stage is the reproductive 'mature zoosporangium', which appears once the immature thallus has reached maximum cell size and the cell body cytoplasm is cleaved into the next generation of zoospores (Fig. 1B).

Representative model strains have an important role to play in understanding the biology of chytrids (Laundon and Cunliffe, 2021). Rhizoclosmatium globosum is a widespread aquatic saprotroph and the strain $R$. globosum JEL800 has emerged as a promising model organism in laboratory investigations (Laundon et al., 2020; Roberts et al., 2020; Venard et al., 2020) due to an available genome (Mondo et al., 2017), easy axenic culture, and amenability to live-cell fluorescent microscopy (Laundon et al., 2020). R. globosum JEL800 exhibits an archetypal chytrid cell plan (Fig. 1B) and rapid life cycle, making it a useful model system to interrogate cellular development (Laundon et al., 2020; Laundon and Cunliffe, 2021).

The chytrid cell cycle has so far been characterised with largely descriptive approaches (e.g Berger et al., 2005) with only a few quantitative studies focusing on specific processes, such as rhizoid morphogenesis (Dee et al., 2019; Laundon et al., 2020) and actin formation (Medina et al., 2020; Prostak et al., 2021). These important studies provide a foundation on which to develop a quantitative approach to understand the biology of the chytrid cell plan and the drivers of the transitions between the life stages. To investigate the cellular and molecular underpinnings of the chytrid life cycle and associated cell biology, we studied the four major life stages 
of the R. globosum cell cycle by combining quantitative volume electron microscopy and transcriptomics (Fig. 1C), with the addition of supplementary targeted live-cell fluorescent microscopy and lipid analysis. The aim of our approach was to quantify the cellular traits that define the major chytrid life stages and identify the biological processes that take place during the developmental transitions between them. As such, we have created a developmental 'atlas' with $R$. globosum for the archetypal chytrid lifecycle, which in turn generated specific avenues for targeted investigation of important biological processes, namely lipid biology, apophysis function, and zoosporogenesis.

By culturing R. globosum and sampling the populations at different stages through their temporal development $(0 \mathrm{~h}$ zoospore, $1.5 \mathrm{~h}$ germling, $10 \mathrm{~h}$ immature thallus, and a $24 \mathrm{~h}$ mixed population including mature zoosporangia) (Fig. 1C), we examined chytrid populations with both 3D reconstructions by Serial Block Face Scanning Electron Microscopy (SBF-SEM) and mRNA sequencing. We used singlecell SBF-SEM reconstructions $(n=5)$ (Suppl. Fig. 1) to quantify the cellular structures at each life stage and population-level transcriptomic analysis of significant KEGG pathway categories ( $n=3$, Differentially Expressed Genes (DEGs)) to identify the major biological differences between the life stages through temporal development (Fig. 1C). As these stages represent key time points in the progression of the linear temporal chytrid life cycle, pairwise comparison of transcriptomes from contiguous life stages achieved an account of the major putative biological transitions (e.g. germling vs. zoospore, immature thallus vs. germling) (Fig. 2C; Suppl. Figs 2-5). Our findings provide insights into chytrid developmental processes and serve as a resource from which to resolve the biology of this ecologically and evolutionary important fungal lineage. 


\section{RESULTS}

\section{A cellular and molecular atlas of Rhizoclosmatium globosum}

126

The orientation, subcellular localisation, and morphology of the cellular ultrastructure determined with SBF-SEM of the $R$. globosum zoospore, germling, and immature thallus life stages are shown in (Fig. 2A; Movie 1; Suppl. Mov. 1-21; Suppl. File 1), with the volumetric transition from zoospore $\left(20.7 \pm 1.7 \mu \mathrm{m}^{3}\right)$ to germling $(33.0 \pm 2.0$ $\left.\mu \mathrm{m}^{3}\right)$ to immature thallus $\left(1,116.3 \pm 206.2 \mu \mathrm{m}^{3}\right)$ exceeding an order of magnitude. These ultrastructural differences in the cell patterns at each life stage (Fig. 2B-D) are complemented with differential gene expression analysis focusing on characterising the transitions between life stages (Fig. 2E-J). Full statistical details of cell volumetric and molecular comparisons are provided in (Suppl. Fig. 5-7; Suppl Tables 1-5; Suppl. File 2). As the mature zoosporangium samples were taken from a mixed population of cell stages (Fig. 1C), they were conservatively excluded from comparison with the first three stages and will be treated separately in this analysis.

The zoospore cell body is a prolate spheroid with an apical flagellum and is volumetrically dominated by a structurally distinct ribosome cluster $(20.5 \pm 2.8 \%)$ in the cell interior which was not detected in the other life stages (Fig. 2A-B; Suppl. Fig. 2; Suppl. Mov. 1-5). The loss of the ribosome cluster in the germling from the zoospore stage matched a downregulation of ribosome and ribosome biogenesis KEGG categories in the germling relative to the zoospore (Fig. 2G; Suppl. File 2). There was no observed significant molecular signature associated with elevated protein synthesis in zoospores, suggesting that ribosome presence and aggregation, but not activity, govern chytrid zoospores. Only two other KEGG categories were 
downregulated in germlings relative to zoospores. These were linked to peroxisomes and ATP-binding cassette (ABC) transporters (Fig. 2G), both of which are associated with lipid metabolism (discussed further below).

Following encystment, the germling stage marks the origin of a complete cell wall, Golgi apparatuses ( 3 out of 5 replicates), and peripheral bodies i.e. vesicular structures bound to the cell periphery putatively associated with cell wall deposition (Fig. 2A\&C; Suppl. Fig. 2; Suppl. Mov. 6-10), as well as the beginning of rhizoid growth from an apical germ tube. Transcriptome analysis indicated that the germling exhibits a greater range of active processes compared to the zoospore, with upregulation of primary and secondary metabolism (e.g. amino acid and secondary metabolite biosynthesis), feeding and energy release (e.g. carbon metabolism and Tricarboxylic Acid Cycle), and transcription and translation (e.g. spliceosome and aminoacyl-tRNA biosynthesis) KEGG categories (Fig. 2H). A similar pattern is shown when comparing KEGG categories downregulated in immature thalli relative to germlings (Fig. 2I). In the germling stage, we also show upregulation of genes associated with proteasome activity (Fig. 2H). Taken together, these data show that the transition from zoospore to germling is characterised by the apparent activation of diverse biological processes including central metabolic pathways, cellular anabolism, and feeding.

Compared to the germling, immature thalli devoted a smaller volumetric proportion to the cell wall (IT $2.4 \pm 0.3 \%$ vs $G 7.6 \pm 1.2 \%, p<0.01$ ) and peripheral bodies (IT $0.3 \pm 0.1 \%$ vs G $1.7 \pm 0.3 \%, p<0.01$ ) (Fig. 2A\&D; Suppl. Fig. 5; Suppl. Mov. 11-15). Similarly, nuclei (IT $4.8 \pm 2.5 \%$ vs G $12.2 \pm 0.5 \%, p<0.01$ ) and mitochondria (IT $7.0 \pm 0.1 \%$ vs G $9.1 \pm 0.7 \%, p<0.001$ ) occupied a smaller volumetric proportion (Fig. 2A\&D; Suppl. Fig. 5). Conversely, immature thalli displayed larger glycogen 
stores (IT $9.4 \pm 2.0 \%$ vs G $1.3 \pm 0.4 \%, p<0.01$ ) and vacuole fractions (IT $13.0 \pm 1.8 \%$ vs G 7.6 $\pm 0.9 \%, p<0.001$ ) than germlings (Fig. 2A\&D; Suppl. Fig. 5). Quantification of the increased vacuolisation of immature thalli in the SBF-SEM reconstructions was correlated with upregulation of related KEGG categories including endocytosis and phagosomes relative to germlings (Fig. 2J). Within these categories are genes related to microtubules and actin, including actin-related proteins-2/3 (ARP2/3), indicating that the immature thalli are associated with higher cytoskeletal activity compared to germlings. Some immature thallus replicates were multinucleate

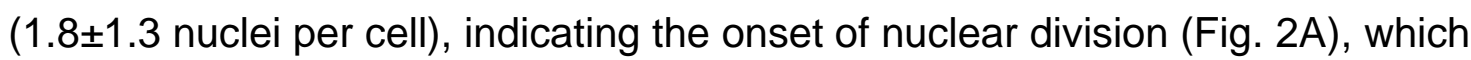
matched the upregulation of cell cycle and DNA replication KEGG categories relative to germlings. The apophysis $\left(12.2 \pm 6.0 \mu \mathrm{m}^{3}\right)$ was observed at the immature thallus stage (discussed further below). Overall, these data show that the biological shift from germling to immature thallus is characterised by a move from initiating general metabolic activity to intracellular trafficking and the start of zoosporogenesis.

As anticipated, the SBF-SEM reconstructions showed that the zoospore is wall-less unlike the germling and immature thallus stages (Fig. 2). Single cell fluorescent-labelling of chitin (the primary wall component) however showed that precursory material is produced by zoospores at the apical pole near the flagellum base (Fig $3 \mathrm{~A}$ ) suggesting that cell wall production is initiated to some extent during the free-swimming zoospore stage of the $R$. globosum cell cycle. In a previous study (Laundon et al., 2020), we identified twenty-eight candidate genes for glycosyltransferase (GT2) domain-containing proteins putatively involved in chitin synthesis in R. globosum and searched for their individual regulation in the transcriptome data. There was no clear pattern of differential regulation of these genes between the life stages overall, however five putative chitin synthase genes 
were upregulated during the zoospore stage (Suppl. File 2). Nine genes were only found upregulated in the thallus relative to the germling, six of which had $>5$-fold change increase in abundance. Six genes were not recovered in any the transcriptomes. Interestingly, a putative $\beta$-1,6-glucan synthase gene (ORY39038) identified in (Laundon et al., 2020) as having a possible role in wall formation in $R$. globosum was downregulated in germlings relative to wall-less zoospores. Together, this suggests that cell wall formation is a dynamic process throughout the chytrid life cycle, with alternative synthesis enzymes employed at different stages.

Changes in subcellular lipid-associated structures are linked with variation in lipid composition

Fluorescent labelling and SBF-SEM reconstructions showed that zoospores and germlings possess a single lipid globule $\left(Z\right.$ 0.9 \pm 0.6 and $\left.G 1.9 \pm 1.1 \mu \mathrm{m}^{3}\right)$ whereas immature thalli have multiple $(68.8 \pm 55.2)$ but smaller $\left(0.5 \pm 0.8 \mu \mathrm{m}^{3}\right)$ globules scattered throughout the cell body (Fig. 3A-B; Movie 2). The lipid globule (red) in the zoospore and germling stages was associated with an apically oriented structure called the rumposome (grey), which is a chytrid-specific organelle putatively associated with cell signalling (Powell, 1983), and a basally oriented microbody (pink) that likely functions as a lipid-processing peroxisome (Powell, 1976) (Fig. 3BC; Movie 2). Together these structures form the lipid-rumposome-microbody (LRM) complex. The rumposome was larger in zoospores than in germlings $(Z 0.3 \pm 0.0 \%$ vs G $0.1 \pm 0.1 \%, p<0.001$ ) (Suppl. Fig. 5), indicating increased activity in zoospores. In immature thalli, LRM complexes were not detected. Unlike in zoospores and germlings, the bulk of the lipids in the immature thalli were intravacuolar $(89.8 \pm 8.5 \%$ 
total lipids) (Fig. 3D). There was no proportional volumetric difference in lipid fractions determined with SBF-SEM reconstructions between the three life stages (Z $4.3 \pm 2.6 \%$ vs G $5.7 \pm 3.7 \%$ vs IT $4.0 \pm 1.6 \%, p>0.05$ ) (Fig. 2B-D; Suppl. Fig. 5).

Live-population imaging of Nile Red-labelled storage lipids showed that initially $(0-2 h)$ the chytrid life cycle was characterised by a decrease $(-49.7 \pm 9.8 \%)$ in lipid fluorescence suggesting that neutral storage lipid catabolism was taking place, before fluorescence increased suggesting that lipid anabolism was occurring up to zoospore release (Fig. 3E-F). The initial lipid fluorescence decreased even in the presence of a carbon replete growth medium in line with the non-feeding habit of zoospores (Fig. 3F). Live-single cell imaging revealed a similar response as shown at the population level, and additionally showed that the zoospore lipid globule remains intact and detectable until at least the point of visible lipid anabolism in the developing cell when the globule becomes undisguisable from the new lipids (Fig. 3G, Movie 3; Suppl. Mov. 22).

Extraction and quantification of lipids from cells harvested at the major life stages showed shifts in lipid profiles. Individual zoospores possessed $1.2 \pm 0.1 \mathrm{pg}$, germlings $2.2 \pm 0.3 \mathrm{pg}$, and immature thalli $904.5 \pm 201.0 \mathrm{pg}$ of lipid per cell (Fig. $3 \mathrm{H}$ ), however lipid composition as a percentage of dry mass ( $Z 74.8 \pm 11.8 \%$ vs $G$ 69.5.0 $\pm 11.5 \%$ vs IT $61.0 \pm 3.3 \%$ ) was similar across the life stages (Fig. $3 \mathrm{I}$ ). Sphingolipids were present in both zoospores and immature thalli $(Z 41.6 \pm 3.6 \%$ and IT $11.5 \pm 2.6 \%$ ), but below detection in germlings (Fig. 3J). Likewise, glycolipids were present in both zoospores $(40.7 \pm 27.1 \%)$ and immature thalli $(40.6 \pm 27.3 \%)$, but below detection in germlings. Conversely, polar lipids were below detection in zoospores yet present in germlings $(51.7 \pm 27.5 \%)$ and immature thalli $(74.0 \pm 3.4 \%)$. 

germlings (Fig. 2G). Most of the genes identified under the peroxisome category are involved in lipid oxidation and acyl-CoA metabolism, and therefore likely involved in the catabolic processing of the lipid globule (Suppl. File 2). Lipid reductases were also detected, which have previously been identified with phospholipid anabolism (Lodhi and Semenkovich, 2014) and, together with the increase in endomembrane between germlings and zoospores determined with SBF-SEM (Figure 2B-C), point to increased phospholipid synthesis for membrane production. ABC-transporters are also involved in lipid transport into peroxisomes from lipid stores (Tarling et al., 2013). Together, these results suggest that glycolipid, and potentially sphingolipid, catabolism likely form part of storage lipid utilisation from the globule via the peroxisome, and polar lipid anabolism for endomembrane production are biological characteristics of the transition from zoospore to germling. germling stage (Fig. 2J) coinciding with new lipids being produced (Fig. 3). The genes were associated with similar acyl-CoA pathways as the zoospore peroxisome category, in addition to alcohol and aldehyde dehydrogenation (Suppl. File 2). Interestingly, although the peroxisome category was also upregulated in immature thalli, the associated genes were not identical to those in zoospores. Many similar acyl-CoA metabolic signatures were shared (16 genes), but with the addition of alcohol and isocitrate dehydrogenation and superoxide dismutase activity. This 
degradation and lipid anabolism, illustrating that some aspects of lipid catabolism and conversion in zoospores are bidirectionally repurposed for anabolism in immature thalli.

\section{The apophysis is a compartmentalised junction for intracellular trafficking} between the rhizoids and cell body

The apophysis is ubiquitous across the Chytridiomycota (James et al., 2006), but the function of the structure is poorly understood (Laundon and Cunliffe, 2021). Here we show that the apophysis exhibits high endomembrane density and active intracellular trafficking between the feeding rhizoids and cell body (Fig. 4). Live-population imaging of FM1-43 labelled endomembrane in R. globosum cells (excluding apophysis and rhizoids) showed stability in fluorescence at the beginning of the life cycle (0-2 h), before a constant increase to the point of zoospore release (Fig. 4A). Matching this, SBF-SEM reconstruction revealed that immature thalli devoted a larger proportion of cell body volume to endomembrane than zoospores and germlings ( $Z 2.3 \pm 1.5 \%$ vs G $7.6 \pm 0.9 \%$ vs IT $13.0 \pm 1.8 \%, p<0.001)$, as well as vacuoles (Fig. 2B-D, Fig. 4B; Suppl. Fig. 5). The associated upregulation of KEGG categories such as protein processing in the endoplasmic reticulum (ER) and ubiquitin mediated proteolysis (Fig. 2J) with the transition from the germling to the immature thallus stage suggests that this structural endomembrane is at least in part ER and coupled with protein turnover.

The immature thalli SBF-SEM reconstructions showed that apophyses displayed even greater structural endomembrane than their corresponding cell bodies (apophysis $12.2 \pm 5.2 \%$ vs cell body $2.7 \pm 0.6 \%, p<0.01$ ) (Fig. 4C-D; Suppl. 
Fig. 6; Movie 4). Apophyses also had comparatively more cell wall than the larger cell bodies (A $11.0 \pm 0.5 \%$ vs CB $2.4 \pm 0.3 \%, p<0.01$ ) (Fig. 4D; Suppl. Fig. 6). In $R$. globosum the cytoplasm between the apophysis and the cell body is connected via an annular pore $(0.40 \pm 0.07 \mu \mathrm{m}$ in diameter $)$ in a distinctive chitin-rich pseudo-septum (Fig. 4 E\&G), causing spatial division within the immature thallus cell plan. Live single cell imaging showed dynamic endomembrane activity in the apophysis linking the intracellular traffic between the rhizoid system and apical base of the cell body via the pore (Movie 5; Suppl. Mov. 23). Taken together, we propose that a function of the apophysis is to act as a cellular junction that regulates intracellular traffic and channels material from feeding rhizoids through the pseudo-septal pore to the cell body dedicated for reproduction.

\section{Developing zoospores in the zoosporangium display an amoeboid morphology}

\section{resulting from endocytotic trafficking}

Understanding zoosporogenesis, including how the thallus differentiates into the next generation of zoospores, is integral to closing the chytrid life cycle. We were unable to achieve a synchronised population of mature zoosporangia, however imaging and sequencing of mixed populations ( $4 \%$ cells at the mature zoosporangia stage, Suppl. Fig. 8) still allowed structural characterisation of this life stage, including the SBF-SEM reconstruction of an entire mature zoosporangium containing 82developing zoospores (Fig. 5; Suppl. Fig. 2; Movie 6; Suppl. Mov. 16). Mature zoosporangia are characterised by internal membrane cleavage (Fig. 5A) where coenocytic immature cytoplasm and organelles are allocated into nascent zoospores. The volume of the SBF-SEM reconstructed mature zoosporangium was 
$3,651.5 \mu \mathrm{m}^{3}$, showing that a single chytrid cell volumetrically increases by more than two orders of magnitude over its entire life cycle. The developing zoospores were flagellate, with the flagellum coiled round the cell body in two neat and complete rotations (Fig. 5B). Zoospores are held within the cell wall of the zoosporangium during zoosporogenesis (Fig. 5B), before exiting through the basally oriented discharge pore (an aperture in the cell wall) when developed. During development, the pore is obstructed by a fibrillar discharge plug (49.7 $\mathrm{\mu m}^{3}$ in volume) (Fig. $\left.5 \mathrm{C}\right)$. visualisation of developing zoospores in context, but to understand the detailed structural basis of this process it was necessary to reconstruct individual zoospore cells in the zoosporangium at higher resolution for comparison with free-swimming zoospores (Fig. 5D-G; Suppl. Fig. 7; Suppl. Mov. 17-21). This was coupled with comparison of transcriptomes from the mature zoosporangia (taken from the mixed populations) with transcriptomes from the free-swimming zoospores. Relative to mature free-swimming zoospores, developing zoospores in the zoosporangium displayed an amoeboid morphology and had greater intracellular trafficking, characterised by a larger volumetric proportion of endomembrane (DZ $1.7 \pm 0.3 \%$ vs $M Z 0.9 \pm 0.4 \%, p<0.05)$, vacuoles, (DZ 8.4 $\pm 2.1 \%$ vs $M Z 2.3 \pm 1.5 \%, p<0.001)$ and the presence of Golgi apparatuses and a vesicle class not observed in mature freeswimming zoospores (Fig. 5D-E; Suppl. Fig. 7). Developing zoospores in the zoosporangium also exhibited larger glycogen stores (DV 5.5 $\pm 1.5 \%$ vs MV $1.6 \pm 1.2$ $\%, p<0.01)$, indicating that glycogen utilisation occurs between the two stages, and a smaller rumposome (DV $0.1 \pm 0.0 \%$ vs $M Z 1.3 \pm 0.0 \%, p<0.001$ ) (Fig 5D-E) than their mature free-swimming counterparts. 

endocytotic engulfment activity, where vacuoles extended from within the zoospore cell interior to the surrounding interstitial maternal cytoplasm of the zoosporangium (Fig. 5F-G). The transcriptome of the mature zoosporangia stage showed an upregulation of phagosome genes relative to the free-swimming zoospore stage (Fig. 5I). The zoospore vacuoles contained electron-dense cargo similar to lipids (Fig. 5F). The prominence of this engulfment across replicates suggests that endocytosis is the primary mode by which resources are trafficked from the maternal cytoplasm into developing zoospores post-cleavage, and that zoospore development does not cease once cleavage has been completed. Notably, developing zoospores did not yet display a detectable ribosomal cluster, as in the free-swimming zoospores (Fig. 2), and the only KEGG categories higher in free-swimming zoospores than in the mature zoosporangia samples were associated with ribosomes (Fig. 5J), indicating that this structure is formed later in zoospore development than captured here. The apparent importance of maintaining ribosomes in the biology of zoospores closes the chytrid life cycle when considered with our early discussion on the distinctiveness of zoospores in the zoospore-germling transition.

\section{DISCUSSION}

361 This study into the cellular and molecular biology of $R$. globosum has generated a developmental atlas of an archetypal chytrid life cycle, shedding light on the cell patterns of major life stages and the biological processes governing the transitions between them. Our key findings are summarised in (Fig. 6). 

and dominating feature. Historically called the 'nuclear cap', ribosome clusters have been observed in zoospores throughout the Chytridiomycota (e.g. Koch, 1961) and in the closely related Blastocladiomycota (e.g. Lovett 1963). Lovett (1963) showed in Blastocladiella (Blastocladiomycota), as we show here with R. globosum, the ribosome cluster dissipates during the transition between the free-swimming zoospore and germling stages causing the release of the previously contained ribosomes throughout the cell. Lovett $(1963,1968)$ related the Blastocladiella zoospore ribosome cluster and subsequent dissipation with the biological activity of the cell during the zoospore-germling transition, proposing the role of the cluster was to maintain the ribosomes through the zoospore stage and to spatially isolate the ribosomes to prevent translation occurring until when the cluster dissipates (i.e. the germling stage) and protein synthesis is initiated. Other investigations into protein synthesis in chytrids (Léjohn and Lovett, 1965) and the Blastocladiomycota (Lovett, 1968; Schmoyer and Lovett, 1969) also suggest that translation does not begin until germination and that the zoospore is at least partially dependent on maternallyprovisioned mRNA and ribosomes.

Our transcriptome data add molecular detail to this process, with KEGG categories related to ribosome maintenance downregulated and categories associated with translation and biosynthesis upregulated during the zoosporegermling transition. Similarly, (Rosenblum et al., 2008) detected high levels of transcripts associated with posttranslational protein modification in Batrachochytrium dendrobatidis $(B d)$ zoospores, but low transcriptional activity. Comparable translational activity is seen in dikaryan spore germination (Brambl and Van Etten, 1970; Mirkes, 1974; Rado and Cochrane, 1971). Taken together, the chytrid 
zoospore life stage represents a sophisticated and well-adapted specialised biological repertoire optimised for dispersal to new growth substrates or hosts rather than general metabolism, which is only initiated by the release of the ribosome cluster at the germling stage once favourable conditions are found.

The germling stage is characterised by major cell plan remodelling, including rhizoid growth, and concomitant activation of diverse metabolic pathways. Similar upregulation of metabolic pathways has been observed at the transcriptional level associated with conidial germination in dikaryan fungi (Sharma et al., 2016; Zhou et al., 2018). Interestingly, we detected the upregulation of proteasome genes in the germling relative to the zoospore, which are also necessary for dikaryan germination (Seong et al., 2008; Wang et al., 2011). A previous study into flagellar retraction in $R$. globosum showed that the internalised flagellum is disassembled and degraded in the germling stage, at least partially by proteasome-dependent proteolysis (Venard et al., 2020). Our findings of increased proteasome expression may likewise be associated with flagellar degradation and the recycling of redundant zoospore machinery in the germling.

The immature thallus displayed increased cellular and molecular signatures associated with the reproductive cell cycle, intracellular trafficking, and protein processing. A key structural development was the vacuolisation of the cell body. Highly vacuolated dikaryan cells (El Ghaouth et al., 1994; Gow and Gooday, 1987) are associated with diverse cellular processes including general homeostasis, protein sorting, cell cycling, and intracellular trafficking (Veses et al., 2008), any of which could at least partially explain the high vacuolisation of immature chytrid thalli. Noticeable in the context of chytrid cell biology however is the upregulation of actindriven cytoskeletal genes, including those assigned to the Arp2/3 complex. The role 
of actin in vacuolisation and endocytosis has been demonstrated in yeast (Eitzen et al., 2002; Gachet and Hyams, 2005), similar to our observations here in $R$. globosum. Arp2/3-dependent actin dynamics drive crawling a-motility in some chytrid zoospores when moving freely in the environment (Fritz-Laylin et al., 2017; Medina et al., 2020) and the presence of animal-like actin components that have been lost in multicellular fungi makes chytrids useful models to investigate the evolution of the fungal cytoskeleton (Prostak et al., 2021). Although R. globosum zoospores do not crawl, the immature thallus has actin patches, cables, and perinuclear shells (Prostak et al., 2021). Here we show that, for a non-crawling chytrid, actinassociated genes are upregulated in immature thalli and are associated with a cell stage with high vacuolisation and endocytosis, which could possibly be associated with the early onset of zoosporogenesis.

We did not find any differences in molecular signatures related to cell wall synthesis between the different life stages at the higher categorical level in $R$. globosum, instead we observed individual differentially expressed genes suggesting that the process is dynamic and complex. Higher levels of putative chitin synthase gene transcripts (e.g. ORY39038) in wall-less zoospores was coupled with the detection of precursory cell wall material at the base of the flagellum. $B d$ transcriptomes also show specific transcripts associated with chitin synthesis to be higher in zoospores than in sessile thalli (Rosenblum et al., 2008). Chitin synthase activity has been shown associated with the Blastocladiella emersonii zoospore membrane (Dalley and Sonneborn, 1982). Early initiation of cell wall synthesis warrants further study and may explain why early chemical inhibition induces phenotypic disruptions to normal development in chytrids (Laundon et al., 2020). 
This emphasises the need to include the wall-less zoospore stage in investigations into chytrid cell wall biology.

This study has highlighted the complexity of lipid dynamics across the $R$. globosum lifecycle. Our data show that the volume of the lipid globule, total lipid by volume, and lipid as a percentage of dry mass remain unchanged between zoospores and germlings, yet we observed a shift in lipid type, moving from sphingolipids and neutral glycolipids (likely storage triacylglycerides) to polar lipids (likely membrane-associated phospholipids) between zoospores and germlings. Similarly, during the $B$. emersonii zoospore-germling transition glycolipids decrease and phospholipids increase (Dalley and Sonneborn, 1982). Previous research has characterised fatty acid profiles in chytrids (Akinwole et al., 2014; Gerphagnon et al., 2019; Rasconi et al., 2020) and shown differences between chytrid zoospores and sessile thalli of the same species (Taube et al., 2019). As the Nile Red emission spectrum undergoes a red shift in increasingly polar environments (Bertozzini et al., 2011), we propose that our live-cell data do not quantify the structural degradation of the lipid globule per se but rather biochemical polarisation as neutral storage lipids are catabolised and polar phospholipids are synthesised. The larger volumetric proportion of glycogen stores in developing zoospores over mature free-swimming zoospores also indicates that glycogen catabolism between the two stages contributes to the zoospore energy budget during motility as previously proposed (Powell, 1979).

Changes in lipid profiles were coupled with subcellular ultrastructure in $R$. globosum. The enzymatic function of LRM-associated microbodies as lipolytic organelles has been previously proposed (Powell, 1979, 1977, 1976), where evidence suggests that enzymatic activity increases following germination (Powell, 
1976). From our data, this organelle may have bidirectional function and be associated with lipid production (anabolism and conversion) as well as catabolism. A key component of the LRM is the enigmatic chytrid rumposome, which was larger in zoospores than germlings. Previous hypotheses have proposed that this organelle is associated with environmental reception and signal transduction in flagellar regulation (Dorward and Powell, 1983). An enlarged rumposome in motile zoospores would support a flagellar role, but its retention in germlings implies additional functions, unless there is a prolonged delay in its degradation. The bulk of lipids in immature thalli during anabolism were intravacuolar and comparable intravacuolar inclusions have been identified in chytrid and dikaryan fungi in the past (Beakes et al., 1992; Bourett and Howard, 1994; Lösel, 1990). Intravacuolar lipid droplets have been previously investigated in yeast but in a catabolic capacity (Van Zutphen et al., 2014; Vevea et al., 2015). Although de novo storage lipid synthesis is associated with the ER (Vevea et al., 2015), the vacuoles identified here may cache and aggregate nascent globules as part of the lipid anabolic pathway.

The function of the chytrid apophysis has long been overlooked, despite its ubiquity in the Chytridiomycota (Powell, 1974; Powell and Gillette, 1987; Taylor and Fuller, 1980). Here we provide evidence that the apophysis is a distinct subcellular structure that acts as a junction for dynamic intracellular trafficking from the multiple branches of the rhizoid network into the central cell body. The localisation of high endomembrane activity in the apophysis and subsequent passage through the annular pore in the pseudo-septum into the cell body implicates this structure as a possible regulatory intermediary consolidating the rhizoid network. The ability of multicellular dikaryan fungi to translocate assimilated nutrients through their hyphal network from the site of uptake is sophisticated (van't Padje et al., 2021; Whiteside 
et al., 2019), and the observed analogous endomembrane flow from feeding rhizoids to the cell body in chytrids is perhaps not surprising. However, the localisation of high endomembrane activity to the apophysis and through the pseudo-septum into the cell body implicates this structure as a regulatory and intermediary junction. The pseudo-septation of the apophysis and rhizoids from the cell body is evidence for functional compartmentation (i.e. feeding vs. reproduction) within the thallus of a unicellular fungus. Comparable structures are also present in other chytrid species (e.g. Barr, 2011; Beakes et al., 1992). Division of multicellular dikaryan fungi by septa, where continuity between distinct cytoplasmic compartments is maintained by septal pores, is integral to multicellularity, cellular differentiation, and resilience (Bleichrodt et al., 2015, 2012). The origin of hyphal septa was a major innovation in fungal evolution (Berbee et al., 2017; Nagy et al., 2020) occurring at the node shared by hyphal and rhizoidal fungi (Berbee et al., 2017). The role of the apophysis/cell body pseudo-septum (or an analogous structure) in chytrids in delineating functionally dedicated subcellular compartments may represent an evolutionary precursor to dikaryan septa and differentiation. Therefore, investigating the chytrid apophysis is not only important for understanding intracellular trafficking biology in the phylum, but also the evolution of multicellularity more widely across the fungal kingdom. zoosporangium and comparison with their free-swimming counterparts have added to understanding the underpinning biology of chytrid zoosporogenesis. Perhaps our most striking finding is the amoeboid morphology of developing zoospores, resulting from engulfment, and trafficking structures, suggesting that developing zoospores 
sporogenesis is complex and diverse, it typically involves the septation of hyphal cytoplasm via cell wall synthesis (Cole, 1986; Money, 2016). As walled cells, dikaryan spores are incapable of such engulfment activity and therefore amoeboid zoospores have more in common with their more distant opisthokont relatives in this regard. Nucleariid amoebae (Yoshida et al., 2009), choanoflagellates (Laundon et al., 2019), and various animal cell types (Bayne, 1990) exhibit analogous endocytotic engulfment behaviour as we show here in fungal zoospores. This apparent conservation may indicate that such engulfment behaviour to assimilate subcellular cargo during sporogenesis of wall-less zoospores existed in the last common ancestor of branching fungi and was lost in dikaryan fungi as spores became walled.

In conclusion, our characterisation of the $R$. globosum life cycle has revealed changes in cell structure and associated biological processes driving chytrid development, some of which show analogies in dikaryan fungi and others in 'animal like' cells. As important saprotrophs, parasites, and pathogens, our findings provide information into the cellular processes that underpin the ecological importance of chytrids. In addition, our characterisation of an early-diverging fungus that retains cellular characteristics from the last common ancestor of branching fungi is a step forward in reconstructing the putative biology of this organism. This study demonstrates the utility of developmental studies with model chytrids such as $R$. globosum and reiterates the need for fundamental biology in investigating the function of chytrid cells.

\section{METHODS AND MATERIALS}


Culture maintenance. Rhizoclosmatium globosum JEL800 was maintained on peptonised milk, tryptone, and glucose (PmTG) agar plates (Barr, 1986) in the dark at $23{ }^{\circ} \mathrm{C}$. To collect zoospores, mature plates were flooded with $5 \mathrm{ml} \mathrm{PmTG}$ and the cell suspension was passed through a $10 \mu \mathrm{m}$ cell sieve (pluriSelect) to remove nonzoospore life stages. Zoospore density was quantified under a Leica DM1000 (10 x objective) with a Sedgewick Raft Counter (Pyser SCGI) diluted to 1:1000 and fixed in $0.2 \%$ formaldehyde. Zoospores were diluted to a working density of $3 \times 10^{6} \mathrm{ml}^{-1}$ prior to inoculation for all light microscopy experiments.

Cell harvesting for SBF-SEM, transcriptomics, and lipid quantification. $R$. globosum was grown to progress through the life cycle and sampled at key time points: $0 \mathrm{~h}$ (zoospore), $1.5 \mathrm{~h}$ (germling), $10 \mathrm{~h}$ (immature thalli), and at $24 \mathrm{~h}$ when the population was a mix of stages including mature zoosporangia (Fig. 1C, Suppl. Fig. 8). For zoospores, each replicate was harvested from $10 \mathrm{ml}$ of undiluted cell suspension immediately after plate flooding. For germlings, each culture flask (83.3910, Sarstedt) contained $40 \mathrm{ml}$ of liquid PmTG and was inoculated with $10 \mathrm{ml}$ of zoospore suspension, incubated for $1.5 \mathrm{~h}$, and pelleted after scraping the flask with an inoculation loop to dislodge adherent cells. Immature thalli replicates were pooled from 10 x culture flasks of $25 \mathrm{ml}$ liquid PmTG inoculated with $50 \mu$ zoospore suspension and incubated for $10 \mathrm{~h}$. Mixed $24 \mathrm{~h}$ populations containing mature zoosporangia were harvested and strained through a $40 \mu \mathrm{m}$ cell strainer (11587522,

557 FisherBrand) to remove smaller life stages. All incubations were conducted at $23^{\circ} \mathrm{C}$ and cells were pelleted at 4,700 rpm for $5 \mathrm{~min}$. For SBF-SEM, cell pellets were resuspended and fixed in $2.5 \%$ glutaraldehyde in $0.1 \mathrm{M}$ cacodylate buffer $\mathrm{pH} 7.2$.

560 Cells were harvested identically for RNA Seq $(n=3)$ with the exception that the supernatant was removed before being flash frozen in liquid nitrogen and stored at - 
$80^{\circ} \mathrm{C}$. Sub-samples from cell pellets were diluted $1: 1000$, fixed in $0.2 \%$

formaldehyde, and stained with FM 1-43FX to visualise cell membranes in order to qualitatively confirm the synchronicity of cultures under a confocal microscope (see further below) before being processed further (Suppl. Fig. 8). Cell pellets were harvested for lipid extraction and quantification as per RNA samples $(n=3)$.

SBF-SEM imaging and reconstruction. Samples were further fixed in buffered glutaraldehyde, pelleted, and embedded in either agar or Bovine Serum Albumin (BSA) gel. Blocks were processed into resin using a modified protocol by Deerinck and colleagues (https://tinyurl.com/ybdtwedm). Briefly, gel-embedded chytrids were fixed with reduced osmium tetroxide, thiocarbohydrazide, and osmium tetroxide, before being stained with uranyl acetate and lead aspartate. Stained blocks were dehydrated in an ethanol series, embedded in Durcupan resin, and polymerised at $60{ }^{\circ} \mathrm{C}$ for $24-48 \mathrm{~h}$. Blocks were preliminarily sectioned to ascertain regions of interest (ROIs) using transmission electron microscopy (FEI Tecnai T12 TEM). ROls were removed from the resin blocks and remounted on aluminium pins, which were aligned using scanning electron microscopy (Zeiss GeminiSEM) on a Gatan 3 view serial block face microtome and imaged.

Stacks of chytrid cells were acquired at $75 \mathrm{~nm}$ z-intervals with an $\mathrm{XY}$ pixel resolution of $2 \mathrm{~nm}$ (zoospore, germling, and developing zoospore inside a mature zoosporangium), $4 \mathrm{~nm}$ (immature thallus), and $8 \mathrm{~nm}$ (mature zoosporangium). Although $X Y$ pixel size differed between life stages, 2-4 nm resolutions were above the minimum sampling limits for quantitative comparison of reconstructed organelles. Due to the lack of replication, the mature zoosporangium was only considered qualitatively. Acquired stacks were cropped into individual cells $(n=5)$ and imported into Microscopy Image Browser (MIB) (Belevich et al., 2016) for reconstruction. Prior 
to segmentation, images were converted to 8-bit, aligned, contrast normalised across z-intervals using default parameters, and then were processed with a Gaussian blur filter (sigma $=0.6$ ). Stacks were segmented using a combination of manual brush annotation and the semi-automated tools available in MIB (Suppl. Fig. 1). Briefly, flagella, lipids, microbodies, nuclei, ribosomal clusters, rumposomes, peripheral bodies, striated inclusions, vacuoles, and vesicles were segmented manually using interpolation every 3-5 slices where appropriate; the discharge plug, endomembrane, glycogen granules, Golgi apparatuses, and mitochondria were masked by coarse manual brushing and then refined by black-white thresholding; and cell boundaries were segmented using the magic wand tool. All models were refined by erosion/dilation operations and manually curated. Models were also refined by statistical thresholding at size cut-offs for each structure consistent across all life stages (either 500 or 1000 voxels).

Structures were volumetrically quantified within MIB. For visualisation of reconstructed cells .am model files were resampled by $33 \%$ in $\mathrm{XY}$ and imported as arealists into the Fiji (Schindelin et al., 2012) plugin TrakEM2 (Cardona et al., 2012), smoothed consistently across life stages, and exported as 3D .obj meshes for final rendering in Blender v2.79. All quantification was conducted on unsmoothed models scaled by $50 \%$. Flagella and rhizoids were excluded from quantification as they are not a component of the cell body, and their total length were not imaged in this study. The unassigned cytosol fraction was defined as the total volume of assigned organelles subtracted from the total cell volume and is inclusive of small structures such as ribosomes, vesicles, and small endomembrane and glycogen objects that could not be confidently assigned and were conservatively excluded. Only 
endomembrane not considered to be predominantly structural (i.e. an organelle or cell-compartment boundary) was reconstructed in the endomembrane category.

RNA extraction. RNA was extracted from the cell pellets using the RNeasy extraction kit (Qiagen) following the manufacturer's instructions with minor modifications. Cell pellets were thawed in $600 \mathrm{ml} \mathrm{RLT}$ lysis buffer containing $10 \mu \mathrm{l}$ $\mathrm{ml}^{-1}$ of 2-mercaptoethanol and lysed at room temperature for 5 min with periodic vortexing. Cell debris was removed by centrifuging at $8000 \mathrm{xg}$ for $1 \mathrm{~min}$, before the lysate was recovered and passed through a QIA shredder (Qiagen). An equal volume of $100 \%$ ethanol was added to the homogenised lysate before being transferred to a RNeasy extraction column. RNA was then extracted following the manufacturers protocol and included an on-column DNase digestion step using the RNase-Free DNase (Qiagen). RNA was quantified using both a NanoDrop 1000 spectrophotometer (Thermo) and the RNA BR assay kit (Invitrogen) on the Qubit 4 fluorometer (Invitrogen). RNA quality was assessed using the RNA 6000 Nano kit total RNA assay (Agilent) run on the 2100 Bioanalyzer instrument (Agilent).

Sequencing and bioinformatics. Sequencing was carried out using Illumina NovaSeq 6000 technology and base calling by CASAVA, yielding 20,122,633 23,677,987 raw reads by Novogene (www.novogene.com). Raw reads were filtered for adaptor contamination and low-quality reads (ambiguous nucleotides $>10 \%$ of the read, base quality $<5$ for more than $50 \%$ of the read) resulting in $19,665,560-$ 22,917,489 clean reads. Reads were mapped against the JEL800 genome using HISAT2 before differentially expressed genes (DEGs) between life stages were determined using DESeq2 as part of the Novogene pipeline (Love et al., 2014).

634 Transcriptomic profiles were highly conserved between replicates within each of the three life stages (Suppl. Fig. 9). All further analyses were performed in house in R 
v3.6.1 (R Core Team) using output from the Novogene analysis pipeline. Shared genes between life history stages were displayed using UpSetR (Conway et al., 2017). Volcano plots of differentially expressed genes were produced using ggplot2 based upon a conservative threshold of log2FoldChange $>0$, padj $<0.05$. Gene Ontology (GO) and Kyoto Encyclopedia of Genes and Genomes (KEGG) enrichment analysis was carried out using the enricher function in the $\mathrm{R}$ package clusterProfiler v3.12 (Yu et al., 2012) with a threshold of padj < 0.05. Differentially expressed KEGG categories were plotted using the dotplot function (Fig. 2) and GO maps generated using the emapplot function (Suppl. Figs. 10-13). For the purposes of this study, analysis and discussion of KEGG pathways was favoured over GO categories as KEGG pathways allow for a more process-oriented interpretation of activity between the life stages.

Confocal microscopy of subcellular structures. Cell structures were labelled in a $24 \mathrm{~h}$ mixed population with $5 \mu \mathrm{M}$ calcofluor white (chitin), $1 \mu \mathrm{M}$ Nile red (neutral lipid), and $5 \mu \mathrm{M}$ FM1-43 (membranes). Cells were imaged under a $63 \mathrm{x}$ oil immersion objective lens with a Leica SP8 confocal microscope (Leica, Germany). Image acquisition settings were as follows: for cell wall excitation at $405 \mathrm{~nm}$ and emission at 410-500 nm (intensity $0.1 \%$, gain 20); for lipids excitation at $514 \mathrm{~nm}$ and emission at 550-710 nm (intensity $0.1 \%$, gain 50); and for membranes excitation at $470 \mathrm{~nm}$ and 500-650 nm (intensity 5\%, gain 50). All life stages were imaged under identical acquisition settings. Cell wall and lipid images are maximum intensity projections at $0.3 \mu \mathrm{m}$ z-intervals and membrane images are single optical sections.

Live-cell widefield microscopy. Time-lapse imaging of the development of fluorescently labelled subcellular structures was optimised for LED intensity and dye loads that did not interfere with normal cellular development relative to a no-dye 
control (Suppl. Fig. 14). Population-level development was imaged using an epifluorescent Leica DMi8 microscope (Leica, Germany) with a 20 x objective lens, and single-cell development with a $63 \times$ oil-immersion lens. Cell structures were labelled as above, with the exception of $1 \mu \mathrm{M}$ FM1-43 (membrane). Image acquisition settings were as follows: for cell wall excitation at $395 \mathrm{~nm}$ and emission at 435-485 nm (intensity 10\%, FIM 55\%, exposure $350 \mathrm{~ms}$ ); for lipids excitation at 575 $\mathrm{nm}$ and emission at 575-615 nm (intensity 10\%, FIM 55\%, exposure $1 \mathrm{~s}$ ); for membranes excitation at $470 \mathrm{~nm}$ and $500-550 \mathrm{~nm}$ (intensity 10\%, FIM 55\%, exposure $2 \mathrm{~s}$ ); and bright field (intensity 15, exposure $150 \mathrm{~ms}$ ). Images were captured using a CMOS Camera (Prime 95B ${ }^{\mathrm{TM}}$, Photometrics). $500 \mu \mathrm{l}$ of diluted zoospore suspension was applied to a glass bottom dish and cells were allowed to settle in the dark for $15 \mathrm{~min}$. After this, the supernatant was removed and $3.5 \mathrm{ml}$ of dye-containing PmTG was added to the dish and imaged immediately. To prevent thermal and hypoxic stress during the imaging period, the dish was placed into a PSet $2000 \mathrm{CT}$ stage (PeCon, Germany) where temperature was controlled at $22^{\circ} \mathrm{C}$ by an F-25 MC water bath (Julabo, Germany), and the dish was covered by an optically clear film which permits gas exchange. Single images were taken at 15 min intervals for a total of $18 \mathrm{~h}$ for population-level development, and $50 \mu \mathrm{m} z$-stacks $(2 \mu \mathrm{m} \mathrm{z}$ intervals) at an interval of $10 \mathrm{~min}$ for a total of $14 \mathrm{~h}$ for single-cell development. Lipid degradation in live, settled zoospores was likewise imaged using $100 \mu \mathrm{l}$ zoospore suspensions labelled with Nile Red in glass bottom dishes. For comparison, labelled zoospores fixed in $0.2 \%$ formaldehyde were also imaged to control for photobleaching. Cells were imaged at $30 \mathrm{~s}$ intervals for $2 \mathrm{~h}$. To visualise endomembrane trafficking in the apophysis, $100 \mu \mathrm{l}$ of $24 \mathrm{~h}$ mixed PmTG cultures 
stained with $10 \mu \mathrm{M}$ FM 1-43 were likewise imaged in glass bottom dishes under a 63 $\mathrm{x}$ oil immersion objective at $30 \mathrm{~s}$ intervals for $30 \mathrm{~min}$.

Image analysis for live-cell microscopy. Developmental time series of

fluorescently labelled subcellular structures were analysed with a custom workflow normalised intensity in the fluorescence channel. For lipid tracking during single-cell development, images from the lipid channel were converted to maximum intensity projections and lipid globules were automatically detected using differences of of the initial lipid globule was conducted using a simple LAP tracker.

Lipid extraction and quantification. Lipids were extracted using the Bligh and Dyer method (Bligh and Dyer, 1959). Lyophilised culture pellets were submersed in a and sonicated for $10 \mathrm{~min}$ in an ultrasonic bath before being centrifuged at 3,000 rpm for 2 min. The supernatant was collected, and the pellet was re-extracted twice. The combined supernatant was phase separated via addition of DCM and PB (giving an overall ratio of 1:1:0.9 (v/v/v)) and centrifugation at $3000 \mathrm{rpm}$ for $2 \mathrm{~min}$. The lower solvent phases were extracted prior to washing the remaining upper phase twice with DCM. The three lower solvent phases were collected and gently evaporated under oxygen-free nitrogen (OFN) in a water bath held at $25^{\circ} \mathrm{C}(\mathrm{N}-\mathrm{EVAP}$, 
preactivated silica gel $\left(4 \mathrm{~h}\right.$ at $\left.150^{\circ} \mathrm{C}\right)$ columns for fractionation. Lipid fractions were separated by polarity via washing the column with one volume of DCM, followed by one volume of acetone and two volumes of $\mathrm{MeOH}$. Each fraction was collected separately, evaporated to dryness under OFN and weighed.

Statistical analysis. All data were tested for normality and homogeneity assumptions using a Shapiro and Levene's test respectively. If assumptions could be met, then differences between zoospore, germling, and immature thallus volumetric proportions were assessed using ANOVA followed by Tukey HSD posthoc testing, or if not, then by a Kruskal-Wallis followed by a Dunn's posthoc test. If a structure was entirely absent from a life stage (e.g. no cell wall in the zoospore stage) then the life stage was eliminated from statistical analysis to remove zero values and the remaining two life stages were compared using a $t$-test or Mann-Whitney $U$ test depending on assumptions, and then the removed life stage qualitatively assigned as different. The differences between cell bodies and apophyses in the immature thallus life stage, and between mature zoospores and developing zoospores, were compared using either a paired $t$-test or a Mann-Whitney $\mathrm{U}$ test depending on assumptions. All statistical analysis was conducted using the scipy package (Virtanen et al., 2020) run with Python 3.7.3 implemented in Jupyter Notebook 6.0.3.

\section{ACKNOWLEDGEMENTS}

We thank Chris Neal at the Wolfson Bioimaging Facility (University of Bristol) for SBF-SEM optimisation and imaging acquisition. We would also like to thank Joyce Longcore (University of Maine) for providing $R$. globosum JEL800 from her chytrid 
culture collection (now curated by the Collection of Zoosporic Eufungi at the University of Michigan https://czeum.herb.Isa.umich.edu).

\section{COMPETING INTERESTS}

The authors declare no competing interests.

\section{FUNDING}

DL is supported by an EnvEast Doctoral Training Partnership (DTP) PhD studentship funded from the UKRI Natural Environment Research Council (NERC grant no. NE/L002582/1). NC, KE, ST and MC are supported by the European Research Council (ERC) (MYCO-CARB project; ERC grant agreement no. 772584).

\section{AUTHOR CONTRIBUTIONS}

$\mathrm{DL}$ and $\mathrm{MC}$ conceived and designed the study. DL setup the study, collected the samples and performed all microscope-based analysis (except the SBF-SEM optimisation and imaging acquisition). KB extracted the RNA and prepared for transcriptome sequencing. ST performed the lipid analysis. NC processed the transcriptome data and with TM supported associated data interpretation. DL and $M C$, with the help of NC, interpreted the data from the study. DL and MC wrote the manuscript with input from all the co-authors.

\section{DATA AVAILABILITY}


All 3D objects, raw datasets associated with figures, and image analysis scripts can be found as Suppl. Files 1-4, in addition to all movies, processed SBF-SEM stacks, and model files, available for download from Figshare at:

\section{https://tinyurl.com/yww6h9d9.}

Upon acceptance, raw sequencing reads will be deposited in the European Nucleotide Archive under ENA project PRJEB47366.

\section{REFERENCES}

Akinwole PO, Lefevre E, Powell MJ, Findlay RH. 2014. Unique odd-chain polyenoic phospholipid fatty acids present in chytrid fungi. Lipids 49:933-942. doi:10.1007/s11745-014-3934-3

Barr DJS. 2011. Phlyctochytrium arcticum n. sp. (Chytridiales); morphology and physiology.Can. J. Bot. 48:2279-2283. doi:10.1139/B70-330

Barr DJS. 1986. Allochytridium expandens Rediscovered: Morphology, Physiology and Zoospore Ultrastructure. Mycologia 78:439. doi:10.2307/3793048

Barr DJS, Hartmann VE. 1976. Zoospore ultrastructure of three Chytridium species and Rhizoclosmatium globosum. Can J Bot 54:2000-2013. doi:10.1139/b76-214

Bayne CJ. 1990. Phagocytosis and Non-Self Recognition in Invertebrates. Bioscience 40:723-731. doi:10.2307/1311504

Beakes GW, Canter HM, Jaworski GHM. 1992. Comparative ultrastructural ontogeny of zoosporangia of Zygorhizidium affluens and Z. planktonicum, chytrid parasites of the diatom Asterionella formosa. Mycol Res 96:1047-1059. doi:10.1016/S0953-7562(09)80115-9 
Belevich I, Joensuu M, Kumar D, Vihinen H, Jokitalo E. 2016. Microscopy Image Browser: A Platform for Segmentation and Analysis of Multidimensional Datasets. PLoS Biol 14:e1002340. doi:10.1371/journal.pbio.1002340

Berbee ML, James TY, Strullu-Derrien C. 2017. Early Diverging Fungi: Diversity and Impact at the Dawn of Terrestrial Life. Annu Rev Microbiol 71:41-60. doi:10.1146/annurev-micro-030117-020324

Berger L, Hyatt AD, Speare R, Longcore JE. 2005. Life cycle stages of the amphibian chytrid Batrachochytrium dendrobatidis. Dis Aquat Organ 68(1): 5163. doi:10.3354/dao068051

Bertozzini E, Galluzzi L, Penna A, Magnani M. 2011. Application of the standard addition method for the absolute quantification of neutral lipids in microalgae using Nile red. J Microbiol Methods 87:17-23. doi:10.1016/j.mimet.2011.06.018

Bleichrodt RJ, Hulsman M, Wösten HAB, Reinders MJT. 2015. Switching from a unicellular to multicellular organization in an Aspergillus niger hypha. MBio 6(2): e00111-15. doi:10.1128/mBio.00111-15

Bleichrodt RJ, van Veluw GJ, Recter B, Maruyama JI, Kitamoto K, Wösten HAB. 2012. Hyphal heterogeneity in Aspergillus oryzae is the result of dynamic closure of septa by Woronin bodies. Mol Microbio/ 86:1334-1344. doi: $10.1111 / \mathrm{mmi} .12077$

Bligh EG, Dyer WJ. 1959. A rapid method of total lipid extraction and purification. Can J Biochem Physio/ 37:911-917. doi:10.1139/059-099

Bourett TM, Howard RJ. 1994. Enhanced labelling of concanavalin a binding sites in fungal endomembranes using a double-sided, indirect method. Mycol Res 
802

803

804

805

806

807

808

809

810

811

812

813

814

815

816

817

818

819

820

821

822

823

Brambl RM, Van Etten JL. 1970. Protein synthesis during fungal spore germination. V. Evidence that the ungerminated conidiospores of Botryodiplodia theobromae contain messenger ribonucleic acid. Arch Biochem Biophys 137:442-452. doi:10.1016/0003-9861(70)90461-3

Cardona A, Saalfeld S, Schindelin J, Arganda-Carreras I, Preibisch S. 2012. TrakEM2 Software for Neural Circuit Reconstruction. PLoS One 7:38011. doi:10.1371/journal.pone.0038011

Cole GT. 1986. Models of cell differentiation in conidial fungi. Microbiol Rev 50(2): 95-132. doi:10.1128/mmbr.50.2.95-132.1986

Conway JR, Lex A, Gehlenborg N. UpSetR: an R package for the visualization of intersecting sets and their properties. Bioinformatics 33: 2938-2940. doi:10.1093/bioinformatics/btx364

Dalley NE, Sonneborn DR. 1982. Evidence that Blastocladiella emersonii zoospore chitin synthetase is located at the plasma membrane. Biochim Biophys Acta Biomembr 686:65-76. doi:10.1016/0005-2736(82)90152-3

Dee JM, Landry BR, Berbee ML. 2019. Actin guides filamentous rhizoid growth and morphogenesis in the zoosporic fungus Chytriomyces hyalinus. Mycologia 111:904-918. doi:10.1080/00275514.2019.1669999

Dorward DW, Powell MJ. 1983. Cytochemical Detection of Polysaccharides and the Ultrastructure of the Cell Coat of Zoospores of Chytriomyces aureus and Chytriomyces hyalinus. Mycologia 75:209-220. doi:10.1080/00275514.1983.12021657 
Eitzen G, Wang L, Thorngren N, Wickner W. 2002. Remodeling of organelle-bound actin is required for yeast vacuole fusion. $J$ Cell Biol 158:669-679. doi:10.1083/jcb.200204089

El Ghaouth A, Arul J, Wilson C, Benhamou N. 1994. Ultrastructural and cytochemical aspects of the effect of chitosan on decay of bell pepper fruit. Physiol Mol Plant Pathol 44:417-432. doi:10.1016/S0885-5765(05)80098-0

Fisher MC, Garner TWJ. 2020. Chytrid fungi and global amphibian declines. Nat Rev Microbiol 18(6): 332-343. doi:10.1038/s41579-020-0335-x

Frenken T, Alacid E, Berger SA, Bourne EC, Gerphagnon M, Grossart H-P, Gsell AS, Ibelings BW, Kagami M, Küpper FC, Letcher PM, Loyau A, Miki T, Nejstgaard JC, Rasconi S, Reñé A, Rohrlack T, Rojas-Jimenez K, Schmeller DS, Scholz B, Seto K, Sime-Ngando T, Sukenik A, Van de Waal DB, Van den Wyngaert S, Van Donk E, Wolinska J, Wurzbacher C, Agha R. 2017. Integrating chytrid fungal parasites into plankton ecology: research gaps and needs. Environ Microbiol 19:3802-3822. doi:10.1111/1462-2920.13827

Fritz-Laylin LK, Lord SJ, Mullins RD. 2017. WASP and SCAR are evolutionarily conserved in actin-filled pseudopod-based motility. J Cell Biol 216:1673-1688. doi:10.1083/jcb.201701074

Gachet Y, Hyams JS. 2005. Endocytosis in fission yeast is spatially associated with the actin cytoskeleton during polarised cell growth and cytokinesis. J Cell Sci 118:4231-4242. doi:10.1242/jcs.02530

Gerphagnon M, Agha R, Martin-Creuzburg D, Bec A, Perriere F, Rad-Menéndez C, Gachon CMM, Wolinska J. 2019. Comparison of sterol and fatty acid profiles of chytrids and their hosts reveals trophic upgrading of nutritionally inadequate 
Gow NAR, Gooday GW. 1987. Cytological aspects of dimorphism in Candida albicans. Crit Rev Microbiol 15:73-78. doi:10.3109/10408418709104449

Grossart HP, Van den Wyngaert S, Kagami M, Wurzbacher C, Cunliffe M, Rojas354. doi:10.1038/s41579-019-0175-8

James TY, Letcher PM, Longcore JE, Mozley-Standridge SE, Porter D, Powell MJ,

Kagami M, Miki T, Takimoto G. 2014. Mycoloop: Chytrids in aquatic food webs. Front

Kagami M, Motoki Y, Masclaux H, Bec A. 2017. Carbon and nutrients of indigestible pollen are transferred to zooplankton by chytrid fungi. Freshw Biol 62:954-964.

Kagami M, von Elert E, lbelings BW, de Bruin A, Van Donk E. 2007. The parasitic doi:10.1111/fwb.12916 
Klawonn I, Van den Wyngaert S, Parada AE, Arandia-Gorostidi N, Whitehouse MJ, Grossart H-P, Dekas AE. 2021. Characterizing the "fungal shunt": Parasitic fungi on diatoms affect carbon flow and bacterial communities in aquatic microbial food webs. Proc Natl Acad Sci 118:e2102225118. doi:10.1073/pnas.2102225118

Koch, W. 1961. Studies of the motile cells of chytrids. III. Major types. Am J Bot 48(9): 786-788. doi:10.2307/2439652

Laundon D, Chrismas N, Wheeler G, Cunliffe M. 2020. Chytrid rhizoid morphogenesis resembles hyphal development in multicellular fungi and is adaptive to resource availability. Proceedings Biol Sci 287:20200433. doi:10.1098/rspb.2020.0433

Laundon D, Cunliffe M. 2021. A Call for a Better Understanding of Aquatic Chytrid Biology. Front Fungal Biol 0:30. doi:10.3389/FFUNB.2021.708813

Laundon D, Larson BT, McDonald K, King N, Burkhardt P. 2019. The architecture of cell differentiation in choanoflagellates and sponge choanocytes. PLOS Biol 17:e3000226. doi:10.1371/journal.pbio.3000226

Léjohn HB, Lovett JS. 1965. Ribonucleic acid and protein synthesis in Rhizophlyctis rosea zoospores. J Bacterio/ 91:709-717. doi:10.1128/jb.91.2.709-717.1966

Lodhi IJ, Semenkovich CF. 2014. Peroxisomes: A nexus for lipid metabolism and cellular signaling. Cell Metab 19(3): 380-392. doi:10.1016/j.cmet.2014.01.002

Lösel DM. 1990. Lipids in the Structure and Function of Fungal Membranes Biochemistry of Cell Walls and Membranes. In Biochemistry of cell walls and Membranes in Fungi (pp. 119-133). Springer, Berlin, Heidelberg. 
895

896

897

898

899

900

901

902

903

904

905

906

907

908

909

910

911

912

913

914

915

Love MI, Huber W, Anders S. 2014. Moderated estimation of fold change and dispersion for RNA-seq data with DESeq2. Genome Biol 15(12):1-21. doi:10.1186/S13059-014-0550-8

Lovett JS. 1968. Reactivation of ribonucleic acid and protein synthesis during germination of Blastocladiella zoospores and the role of the ribosomal nuclear cap. J Bacterio/ 96:962-969. doi:10.1128/jb.96.4.962-969.1968

Lovett JS. 1963. Chemical and Physical Characterization of "Nucelar Caps" Isolated from Blastocladiella Zoospores. J Bacterio/ 85:1235-1246. doi:10.1128/JB.85.6.1235-1246.1963

Medina EM, Buchler NE. 2020. Chytrid fungi. Curr Biol 30:R516-R520. doi:10.1016/j.cub.2020.02.076

Medina EM, Robinson KA, Bellingham-Johnstun K, laniri G, Laplante C, Fritz-Laylin LK, Buchler NE. 2020. Genetic transformation of Spizellomyces punctatus, a resource for studying chytrid biology and evolutionary cell biology. Elife 9:1-20. doi:10.7554/eLife.52741

Medina EM, Turner JJ, Gordân R, Skotheim JM, Buchler NE. 2016. Punctuated evolution and transitional hybrid network in an ancestral cell cycle of fungi. Elife 5:1-23. doi:10.7554/elife.09492

Mirkes PE. 1974. Polysomes, ribonucleic acid, and protein synthesis during germination of Neurospora crassa conidia. J Bacteriol 117:196-202. doi:10.1128/jb.117.1.196-202.1974

Mondo SJ, Dannebaum RO, Kuo RC, Louie KB, Bewick AJ, LaButti K, Haridas S, 
Kuo A, Salamov A, Ahrendt SR, Lau R, Bowen BP, Lipzen A, Sullivan W,

Money NP. 2016. Spore Production, Discharge, and Dispersal. In The Fungi: $3^{\text {rd }}$ edition (pp. 67-97). Academic Press. doi:10.1016/B978-0-12-382034-1.00003-7

Nagy LG, Kovács GM, Krizsán K. 2018. Complex multicellularity in fungi:

Nagy LG, Varga T, Csernetics Á, Virágh M. 2020. Fungi took a unique evolutionary route to multicellularity: Seven key challenges for fungal multicellular life. Fungal Biol Rev 34(4): 151-169. doi:10.1016/j.fbr.2020.07.002

Otsu N. 1979. Threshold Selection Method From Gray-Level Histograms. IEEE Trans Syst Man Cybern SMC-9:62-66. doi:10.1109/tsmc.1979.4310076

Powell MJ. 1983. Localization of antimonate-mediated precipitates of cations in zoospores of Chytriomyces hyalinus. Exp Mycol 7:266-277. doi:10.1016/0147-

Powell MJ. 1979. The structure of microbodies and their associations with other organelles in zoosporangia of Entophlyctis variabilis. Protoplasma 98:177-198. doi:10.1007/BF01281439 

doi:10.1007/BF00410773

Powell MJ. 1976. Ultrastructure and isolation of glyoxysomes (microbodies) in zoospores of the fungus Entophlyctis sp. Protoplasma 89:1-27. doi:10.1007/BF01279325

Powell MJ. 1974. Fine Structure of Plasmodesmata in a Chytrid. Mycologia 66:606614. doi:10.1080/00275514.1974.12019652

Powell MJ, Gillette L. 1987. Septal Structure of the Chytrid Rhizophlyctis harderi. Mycologia 79:635-639. doi:10.1080/00275514.1987.12025436

Prostak SM, Robinson KA, Titus MA, Fritz-Laylin LK. 2021. The actin networks of chytrid fungi reveal evolutionary loss of cytoskeletal complexity in the fungal

Rado TA, Cochrane VW. 1971. Ribosomal competence and spore germination in Fusarium solani. J Bacteriol 106:301-304. doi:10.1128/jb.106.2.301-304.1971

Roberts C, Allen R, Bird KE, Cunliffe M. 2020. Chytrid fungi shape bacterial communities on model particulate organic matter. Biol Lett 16:20200368. doi:10.1098/rsbl.2020.0368

Rosenblum EB, Stajich JE, Maddox N, Eisen MB. 2008. Global gene expression 
dendrobatidis. Proc Natl Acad Sci USA 105:17034-17039. doi:10.1073/pnas.0804173105

Schindelin J, Arganda-Carreras I, Frise E, Kaynig V, Longair M, Pietzsch T, Preibisch S, Rueden C, Saalfeld S, Schmid B, Tinevez JY, White DJ, Hartenstein V, Eliceiri K, Tomancak P, Cardona A. 2012. Fiji: An open-source platform for biological-image analysis. Nat Methods 9(7): 676-682. doi:10.1038/nmeth.2019

Schmoyer IR, Lovett JS. 1969. Regulation of protein synthesis in zoospores of Blastocladiella. J Bacterio/ 100:854-864. doi:10.1128/jb.100.2.854-864.1969

Seong KY, Zhao X, Xu JR, Güldener U, Kistler HC. 2008. Conidial germination in the filamentous fungus Fusarium graminearum. Fungal Genet Biol 45:389-399. doi:10.1016/j.fgb.2007.09.002

Sharma M, Sengupta A, Ghosh R, Agarwal G, Tarafdar A, Nagavardhini A, Pande S, Varshney RK. 2016. Genome wide transcriptome profiling of Fusarium oxysporum $\mathrm{f} s p$. ciceris conidial germination reveals new insights into infectionrelated genes. Sci Rep 6:1-11. doi:10.1038/srep37353

Tarling EJ, Vallim TQ d. A, Edwards PA. 2013. Role of ABC transporters in lipid transport and human disease. Trends Endocrinol Metab 24(7): 342-350. doi:10.1016/j.tem.2013.01.006

Taube R, Fabian J, Van den Wyngaert S, Agha R, Baschien C, Gerphagnon M, Kagami M, Krüger A, Premke K. 2019. Potentials and limitations of quantification of fungi in freshwater environments based on PLFA profiles. Fungal Ecol 41:256-268. doi:10.1016/j.funeco.2019.05.002 
Taylor JW, Fuller MS. 1980. Microtubules, organelle movement, and cross-wall formation at the sporangial-rhizoidal interface in the fungus, Chytridium confervae. Protoplasma 104:201-221. doi:10.1007/BF01279768

Tedersoo L, Sánchez-Ramírez S, Kõljalg U, Bahram M, Döring M, Schigel D, May T, Ryberg M, Abarenkov K. 2018. High-level classification of the Fungi and a tool for evolutionary ecological analyses. Fungal Divers 90:135-159. doi:10.1007/s13225-018-0401-0

Tinevez JY, Perry N, Schindelin J, Hoopes GM, Reynolds GD, Laplantine E, Bednarek SY, Shorte SL, Eliceiri KW. 2017. TrackMate: An open and extensible platform for single-particle tracking. Methods 115:80-90. doi:10.1016/j.ymeth.2016.09.016

van't Padje A, Werner GDA, Kiers ET. 2021. Mycorrhizal fungi control phosphorus value in trade symbiosis with host roots when exposed to abrupt 'crashes' and 'booms' of resource availability. New Phytol 229:2933-2944. doi:10.1111/nph.17055

van de Vossenberg BTLH, Warris S, Nguyen HDT, van Gent-Pelzer MPE, Joly DL, van de Geest HC, Bonants PJM, Smith DS, Lévesque CA, van der Lee TAJ. 2019. Comparative genomics of chytrid fungi reveal insights into the obligate biotrophic and pathogenic lifestyle of Synchytrium endobioticum. Sci Rep 9:114. doi:10.1038/s41598-019-45128-9

Van Der Walt S, Schönberger JL, Nunez-Iglesias J, Boulogne F, Warner JD, Yager N, Gouillart E, Yu T. 2014. Scikit-image: Image processing in python. PeerJ 2:e453. doi:10.7717/peerj.453 
M, Van Der Klei IJ, Kohlwein SD. 2014. Lipid droplet autophagy in the yeast Saccharomyces cerevisiae. Mol Biol Cell 25:290-301. doi:10.1091/mbc.E13-080448

Venard CM, Vasudevan KK, Stearns T. 2020. Cilium axoneme internalization and degradation in chytrid fungi. Cytoskeleton 77:365-378. doi:10.1002/cm.21637

Veses V, Richards A, Gow NA. 2008. Vacuoles and fungal biology. Curr Opin Microbiol 11(6): 503-510. doi:10.1016/j.mib.2008.09.017

Vevea JD, Garcia EJ, Chan RB, Zhou B, Schultz M, Di Paolo G, McCaffery JM, Pon LA. 2015. Role for Lipid Droplet Biogenesis and Microlipophagy in Adaptation to Lipid Imbalance in Yeast. Dev Cell 35:584-599. doi:10.1016/j.devcel.2015.11.010

Virtanen P, Gommers R, Oliphant TE, Haberland M, Reddy T, Cournapeau D, Burovski E, Peterson P, Weckesser W, Bright J, van der Walt SJ, Brett M, Wilson J, Millman KJ, Mayorov N, Nelson ARJ, Jones E, Kern R, Larson E, Carey CJ, Polat I, Feng Y, Moore EW, VanderPlas J, Laxalde D, Perktold J, Cimrman R, Henriksen I, Quintero EA, Harris CR, Archibald AM, Ribeiro AH, Pedregosa F, van Mulbregt P, Vijaykumar A, Bardelli A Pietro, Rothberg A, Hilboll A, Kloeckner A, Scopatz A, Lee A, Rokem A, Woods CN, Fulton C, Masson C, Häggström C, Fitzgerald C, Nicholson DA, Hagen DR, Pasechnik D V., Olivetti E, Martin E, Wieser E, Silva F, Lenders F, Wilhelm F, Young G, Price GA, Ingold GL, Allen GE, Lee GR, Audren H, Probst I, Dietrich JP, Silterra J, Webber JT, Slavič J, Nothman J, Buchner J, Kulick J, Schönberger JL, de Miranda Cardoso JV, Reimer J, Harrington J, Rodríguez JLC, Nunez-Iglesias J, 
M, Pak M, Smith NJ, Nowaczyk N, Shebanov N, Pavlyk O, Brodtkorb PA, Lee P, McGibbon RT, Feldbauer R, Lewis S, Tygier S, Sievert S, Vigna S, Peterson S, More S, Pudlik T, Oshima T, Pingel TJ, Robitaille TP, Spura T, Jones TR, Cera T, Leslie T, Zito T, Krauss T, Upadhyay U, Halchenko YO, Vázquez-Baeza Y. 2020. SciPy 1.0: fundamental algorithms for scientific computing in Python. Nat Methods 17:261-272. doi:10.1038/s41592-019-0686-2

Wang Y, Kim SG, Wu J, Yu S, Kang KY, Kim ST. 2011. Proteasome inhibitors affect appressorium formation and pathogenicity of the rice blast fungus, Magnaporthe oryzae. Plant Pathol J 27:225-231. doi:10.5423/PPJ.2011.27.3.225

Whiteside MD, Werner GDA, Caldas VEA, van't Padje A, Dupin SE, Elbers B, Bakker M, Wyatt GAK, Klein M, Hink MA, Postma M, Vaitla B, Noë R, Shimizu TS, West SA, Kiers ET. 2019. Mycorrhizal Fungi Respond to Resource Inequality by Moving Phosphorus from Rich to Poor Patches across Networks. Curr Biol 29:2043-2050.e8. doi:10.1016/j.cub.2019.04.061

Yoshida M, Nakayama T, Inouye I. 2009. Nuclearia thermophila sp. nov. (Nucleariidae), a new nucleariid species isolated from Yunoko Lake in Nikko (Japan). Eur J Protisto/ 45:147-155. doi:10.1016/j.ejop.2008.09.004

Yu G, Wang L-G, Han Y, He Q-Y. 2012. clusterProfiler: an R Package for Comparing Biological Themes Among Gene Clusters. Omics: a journal of integrative biology 16(5):284-287. doi:10.1089/OMI.2011.0118

Zhou T, Wang X, Luo J, Ye B, Zhou Y, Zhou L, Lai T. 2018. Identification of differentially expressed genes involved in spore germination of Penicillium expansum by comparative transcriptome and proteome approaches. Microbiology Open 7:e00562. doi:10.1002/mbo3.562 


\section{FIGURE LEGENDS}

1060

1061

1062

1063

1064

1065

1066

1067

1068

1069

1070

1071

1072

1073

1074

1075

1076

1077

1078

1079

1080

1081

Figure 1 Chytrids are an early-diverging fungal phylum with a dimorphic life

cycle. (A) Chytrids (phylum Chytridiomycota) are an early-diverging fungal lineage, many members of which exhibit cellular characteristics retained from the last common ancestor of branching (rhizoidal and hyphal) fungi (star). Simplified phylogenetic tree from (Laundon and Cunliffe, 2021; Tedersoo et al., 2018). (B) Rhizoclosmatium globosum exhibits an archetypal chytrid life cycle and cell plan delineated here into four discrete major stages. Labelled is the apophysis (a), cell body (b), and rhizoids (r). Scale bar $=10 \mu \mathrm{m}$. (C) Diagrammatic workflow of the experimental setup used in this study for comparative cellular Serial Block Face Scanning Electron Microscopy (SBF-SEM) and molecular (transcriptome) analysis.

\section{Figure 2 Serial Block Face Scanning Electron Microscopy (SBF-SEM)} reconstructions and transcriptome analysis provided an atlas of the Rhizoclosmatium globosum life cycle. (A) Representative SBF-SEM reconstructions of the first three life stages of the $R$. globosum lifecycle. Bottom row shows the stages to scale. Organelle colours as in (B-D) and conserved throughout. (B-D) Volumetric composition of assigned organelles in SBF-SEM reconstructions ( $n$ $=5$ ) of zoospores (B), germlings (C), and immature thalli (D). EM = endomembrane, $\mathrm{MB}=$ microbodies, $\mathrm{PB}=$ peripheral bodies, $\mathrm{SI}=$ striated inclusion. $(\mathrm{E})$ Shared and unique gene expression counts between life stages. Inset shows total expressed genes per life stage. (F) Pairwise comparison of differentially expressed genes (DEGs) between germlings and zoospores, and immature thalli and germlings. (G-J) Pairwise comparison of significant $(p<0.05)$ differentially expressed KEGG 
categories between germlings and zoospores $(\mathrm{G}-\mathrm{H})$, and immature thalli and germlings (I-J).

\section{Figure 3 Changes in lipid and lipid-associated cell structures occur with}

transitions between R. globosum life stages. (A) Fluorescent labelling of $R$. globosum shows distinct shifts in lipid structures across the chytrid life cycle and cell wall. Dashed line demarks cell boundary where not labelled in the zoospore.

Zoospore inset shows precursory cell wall material at the flagellar base contrastbrightness adjusted for visualisation. Apophysis (a), cell body (b), flagellum (f), rhizoid (r). Scale bars $=5 \mu \mathrm{m}$. (B) Representative SBF-SEM reconstructions of lipid globules and lipid-associated structures across chytrid life stages. (C-D) Representative single false-coloured SBF-SEM slices (top) and SBF-SEM reconstructions (bottom) of the lipid-rumposome-microbody (LRM) complex from zoospores (also seen in germlings) (C) and intravacuolar lipid globules (D) from immature thalli. Scale bars $=1 \mu \mathrm{m}$. (E) Live-cell imaging $(n=5)$ of $R$. globosum population-level Nile red-stained lipid dynamics. Red $=$ mean lipid fluorescence $( \pm$ $\min / \max )$, black $=$ mean total cell area $( \pm \min / \max )$, dashed line $=$ mean sporulation time of population. (F) Immediately following zoospore settlement, the populationlevel $(n=5)$ lipid fluorescence (red) decreases relative to fixed photobleaching control populations (black). (G) Live-cell imaging revealed differential lipid dynamics across the chytrid life cycle. Note that the original zoospore lipid globule (arrowhead) remains intact up to the point of lipid anabolism in the immature thallus. Timestamp $=$ HH:MM. Scale bar $=10 \mu \mathrm{m}$. (H-J) Lipid analysis shows shifts in lipid composition of the chytrid lifecycle. Lipid quantities as total mass per cell $(\mathrm{H})$ and as a percentage of total dry mass (I) between chytrid life stages. Changes in lipid fractions were found between chytrid life stages $(\mathrm{J})$. Dashed line = below analytical detection. 


\section{Figure 4 The apophysis is a distinct subcellular structure characterised by} increased endomembrane trafficking. (A) Live-cell imaging $(n=5)$ of $R$. globosum population-level FM1-43-stained endomembrane dynamics. Purple $=$ mean endomembrane fluorescence $( \pm \min / \max )$, black $=$ mean total cell area $( \pm \min / \max )$, dashed line $=$ mean sporulation time of population $(B-C)$ Representative SBF-SEM reconstructions of endomembrane across chytrid life stages $(B)$ and the apophysis from immature thalli (C). Volumetric composition of SBF-SEM reconstructions $(n=5)$ of immature thallus apophyses (D). Representative single false-coloured SBF-SEM slice $(E)$ and reconstruction $(F)$ of the endomembrane and thickened cell wall (asterisk) at the apophysis-cell body junction. Fluorescent labelling of the chitin rich wall around the apophysis-cell body connecting pore and associated endomembrane structures $(G)$. Labels as in Fig. 3A. All scale bars $=1 \mu \mathrm{m}$.

\section{Figure 5 Developing zoospores in the zoosporangium have amoeboid}

morphology with endocytotic activity. (A) Fluorescent labelling of lipids, cell wall, and endomembrane in an R. globosum mature zoosporangium. Scale bar $=5 \mu \mathrm{m}$. (B-C) SBF-SEM reconstructions of an 82-zoospore containing mature zoosporangium (B) highlighting the discharge plug, shown in coral (C). (D) Representative SBF-SEM reconstructions of a developing zoospore. Organelle colours as in Fig. 5E. (E) Volumetric composition of SBF-SEM reconstructions of developing zoospores $(n=5)$. (F-G) Representative single false-coloured SBF-SEM slice $(F)$ and reconstruction $(G)$ of the endocytotic vacuoles in developing zoospores. Dashed line delineates the zoospore cell boundary in $(F)$. Scale bar $=1 \mu \mathrm{m} .(H)$ Pairwise comparison of differentially expressed genes (DEGs) between mature zoosporangia and the free-swimming zoospore life stage. (I-J) Pairwise comparison 
of significant differentially expressed KEGG categories between mature zoosporangia and the free-swimming zoospore life stage.

\section{Figure 6 Summary of key components of the chytrid cell plan and biological} processes associated with the transition between stages in the $R$. globosum life cycle. Inner life cycle shows life stages to scale. Grey dashed lines indicate the beginning of the rhizoid system.

Supplementary Figure 1 Workflow of the image analysis protocol used to generate and visualise 3D reconstructions of chytrid cells from SBF-SEM stacks.

Supplementary Figure 2 Examples of subcellular components identified in this study taken from single SBF-SEM slices. (A) Whole cell slices of each chytrid life stage showing the localisation and orientation of subcellular structures in context. (B) High magnification images of individual subcellular structures identified across life stages, where present. (C) Individual subcellular structures largely unique to individual life stages. $a=$ apophysis, $d=$ discharge plug, $e=$ endomembrane, $g=$ glycogen, ga = Golgi apparatus, I = lipid globule, $\mathrm{m}=$ mitochondria, $\mathrm{mb}=$ microbodies, $\mathrm{n}=$ nucleus, $\mathrm{r}=$ ribosomal cluster, $r u=$ rumposome, $\mathrm{s}=$ striated inclusion, $v=$ vacuoles. Asterisks in $(C)$ show electron-dense plate at the base of the zoospore flagella. Scale bars $=1 \mu \mathrm{m}(\mathrm{A})$ and $0.2 \mu \mathrm{m}(\mathrm{B}-\mathrm{C})$.

Supplementary Figure 3 Individual 3D SBF-SEM reconstructions of $R$. globosum cells (not to scale) across life stages labelled with replicate ID's. Organelle colours as in Fig. 2A-D. Top row shows all replicates to scale.

Supplementary Figure 4 Individual volumetric compositions of assigned organelles from $R$. globosum SBF-SEM reconstructions across life stages labelled with replicate ID's. Organelle colours as in Fig. 2A-D. 
Supplementary Figure 5 Comparisons of volumetric proportions of subcellular structures across chytrid life stages $(n=5)$. n.s $p>0.05$ (not significant), ${ }^{*} p<0.05$, ${ }^{* *} p<0.01,{ }^{* * *} p<0.001$.

Supplementary Figure 6 Comparisons of volumetric proportions of subcellular structures between immature thalli cell bodies and their corresponding apophyses ( $n$ $=5$ ). n.s $p>0.05$ (not significant), ${ }^{*} p<0.05,{ }^{* *} p<0.01,{ }^{* * *} p<0.001$.

Supplementary Figure 7 Comparisons of volumetric proportions of subcellular structures between developing and mature zoospores $(n=5)$. n.s $p>0.05$ (not significant), ${ }^{*} p<0.05,{ }^{* *} p<0.01,{ }^{* * *} p<0.001$.

Supplementary Figure 8 Representative images from confocal surveys conducted to assess the synchronicity of cell cultures for SBF-SEM and RNA-Seq harvesting. Cells diluted 1:1000, fixed in $0.2 \%$ formaldehyde, and stained with FM 1-43FX to visualise cell membranes. Asterisks mark mature zoosporangia in mixed populations.

Supplementary Figure 9 Heatmap clustering of all DEGs between zoospore, germling, and immature thallus replicates.

Supplementary Figure $10 \mathrm{GO}$ enrichment map showing significant $(p<0.05)$ differential expression of GO clusters, downregulated in germlings relative to zoospores. Circle size represents numbers of genes, colour represents adjusted $p$ value.

Supplementary Figure $11 \mathrm{GO}$ enrichment map showing significant $(p<0.05)$ differential expression of GO clusters, upregulated in germlings relative to zoospores. Circle size represents numbers of genes, colour represents adjusted $p$ value. 
Supplementary Figure $12 \mathrm{GO}$ enrichment map showing significant $(p<0.05)$ differential expression of GO clusters, downregulated in immature thalli relative to germlings. Circle size represents numbers of genes, colour represents adjusted $p$ value.

Supplementary Figure $13 \mathrm{GO}$ enrichment map showing significant $(p<0.05)$ differential expression of GO clusters, upregulated in immature thalli relative to germlings. Circle size represents numbers of genes, colour represents adjusted $p$ value.

Supplementary Figure 14 Comparison of sporulation times (as a proxy for normal cell development) for dye-labelled chytrid populations $(n=5)$ imaged by live-cell microscopy, relative to no dye-controls. n.s $p>0.05$ (not significant).

\section{MOVIE LEGENDS}

Movie 1 SBF-SEM reconstructions allowed the structural comparison of life stages in R. globosum. Representative SBF-SEM reconstructions of the zoospore, germling, and immature thallus life stages for comparison. Zoospore and germling cells shown to scale at the beginning of the movie, and later enlarged.

Movie 2 Structural shifts in lipid globules were observed across R. globosum life stages, associated with the change from catabolism/conversion to anabolism. Representative SBF-SEM reconstructions of the zoospore, germling, and immature thallus lipid structures for comparison.

Movie 3 The zoospore lipid globule remained as an intact structure across the $\boldsymbol{R}$ globosum life cycle. Automated particle tracking of lipid globules (red) across the chytrid lifecycle. Magenta circles mark individual lipid globules. Yellow track shows 
particle tracking of the initial lipid globule into the period of lipid anabolism. Cell wall shown in cyan. Timestamp $=\mathrm{HH}: \mathrm{MM}$.

Movie 4 The $R$. globosum apophysis is structurally dominated by

endomembrane structures. Representative SBF-SEM reconstruction of a chytrid apophysis from an immature thallus.

Movie 5 The $R$. globosum apophysis regulates intracellular trafficking between

the rhizoids and cell body. Live-cell imaging of endomembrane dynamics in the chytrid apophysis. The apophysis links endomembrane dynamics between the rhizoid system and thallus. Shown are DIC (left), endomembrane (centre), and overlay (right) channels. Timestamp = MM:SS.

Movie 6 SBF-SEM reconstruction of an $\boldsymbol{R}$. globosum mature zoosporangium.

Movie 7 Developing zoospores were more amoeboid than mature zoospores in

R. globosum, due to elevated endocytosis and trafficking. Representative SBF-

SEM reconstructions of the 'mature' zoospore and developing zoospore life stages

1216 for comparison.

Supplementary Movies 1-21 All individual SBF-SEM reconstructions used in this study. Replicates of zoospores (Suppl. Mov. 1-5), germlings (Suppl. Mov. 6-10), immature thalli (Suppl. Mov. 11-15), a mature zoosporangium (Suppl. Mov. 16), and developing zoospores (Suppl. Mov. 17-21).

Supplementary Movie 22 Replicates of automated particle tracking of lipid globules (red) across the chytrid lifecycle. Magenta circles mark individual lipid globules. Yellow track shows particle tracking of the initial lipid globule into the period of lipid anabolism. Cell wall shown in cyan. Timestamp $=\mathrm{HH}: \mathrm{MM}$. 
Supplementary Movie 23 Replicates of live-cell imaging of endomembrane dynamics in the chytrid apophysis. The apophysis links endomembrane dynamics between the rhizoid system and thallus. Shown are DIC (left), endomembrane (centre), and overlay (right) channels. Timestamp $=$ MM:SS.

\section{SUPPLEMENTARY TABLES}

Supplementary Table 1. Volumetric quantities of cellular structures recorded across chytrid life stages.

Supplementary Table 2. Numerical quantities of cellular structures recorded across chytrid life stages.

Supplementary Table 3. Volumetric percentages and statistical comparisons of cellular structures recorded across chytrid life stages.

Supplementary Table 4. Volumetric percentages and statistical comparisons of cell bodies and their corresponding apophyses in immature thalli.

Supplementary Table 5. Volumetric percentages and statistical comparisons of free-swimming and developing zoospores.

\section{SUPPLEMENTARY FILES}

Supplementary File 1 All SBF-SEM reconstructions available as 3D objects.

Supplementary File 2 Raw data associated with figures and in-text discussions presented in this study. 
1246 Supplementary File 3 Python script used to quantify population level fluorescence

1247 of developing chytrid cells (Fig. 3E, Fig. 4A).

1248 Supplementary File 4 Python script used to quantify single-cell Nile Red

1249 fluorescence of settled chytrid zoospores (Fig. 3F). 
bioRxiv preprint doi: https://doi.org/10.1101/2021.09.06.459148igtult@erłion posted September 6, 2021. The copyright holder for this
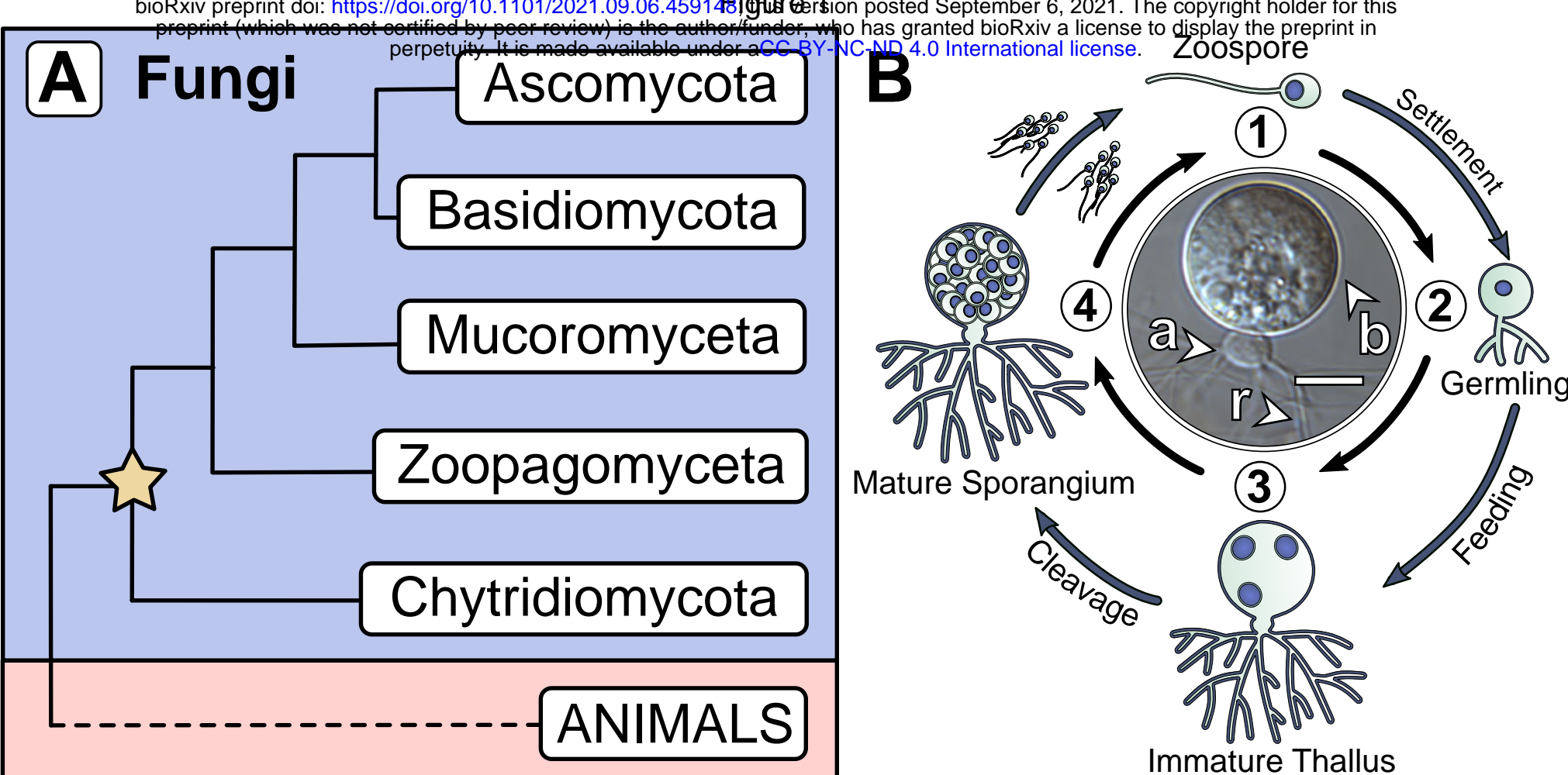

C
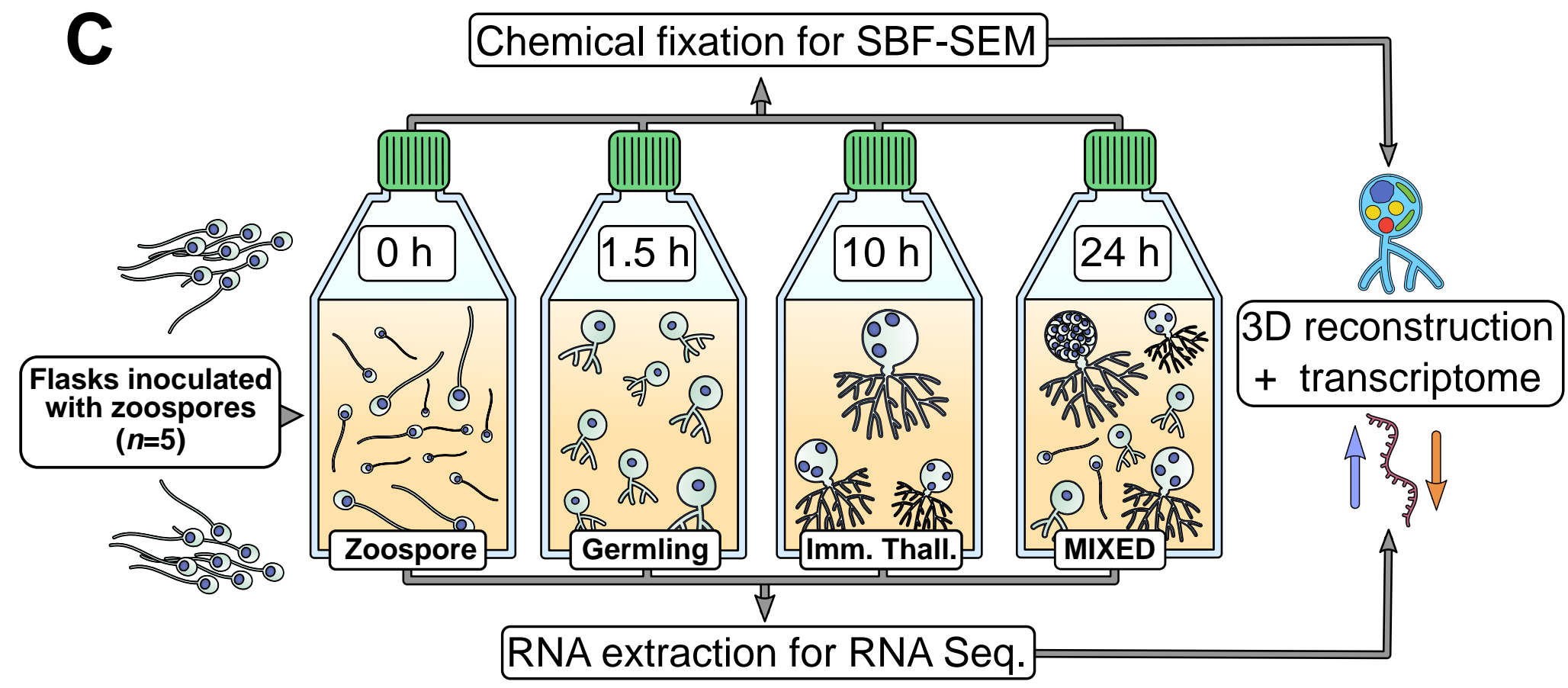


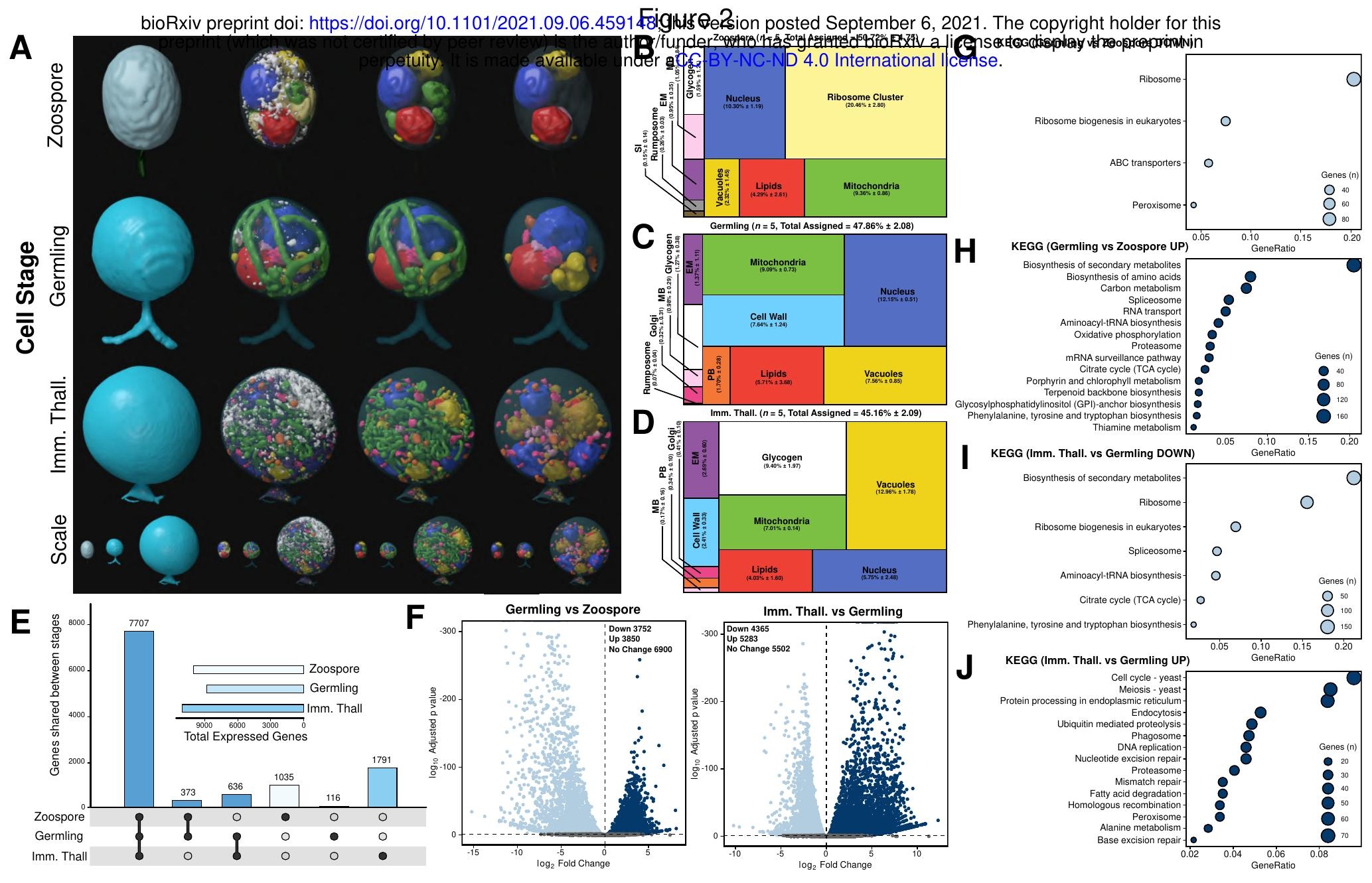


bioRxiv preprint doi: https://doi.org/10.1101/2021.09.06.45914E;iglsker5on posted September 6, 2021. The copyright holder for this

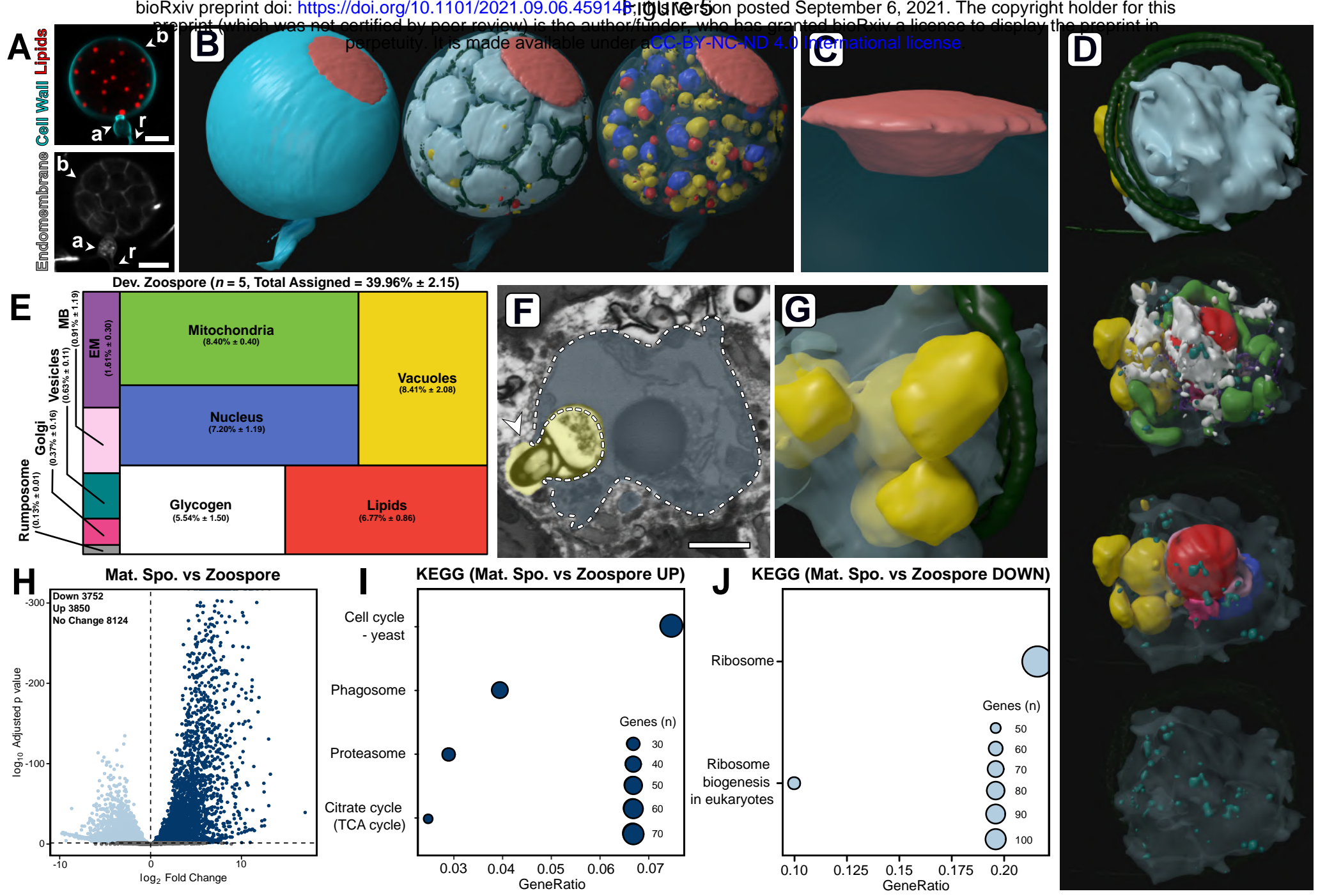


bioRxiv preprint doi: https://doi.org/10.1101/2021.09.06.45914Fithigrerfon posted September 6, 2021. The copyright holder for this preprint (which was not certified by peer review) is the author/funder, who has granted bioRxiv a license to display the preprint in perpetuity. It is made avain under aCC-BY-NC-ND 4.0 International license.

- Neutral lipid degradation

- Rumposome shrinking

- Polar lipid synthesis

- Flagellar retraction

(1) ENCYSTMENT

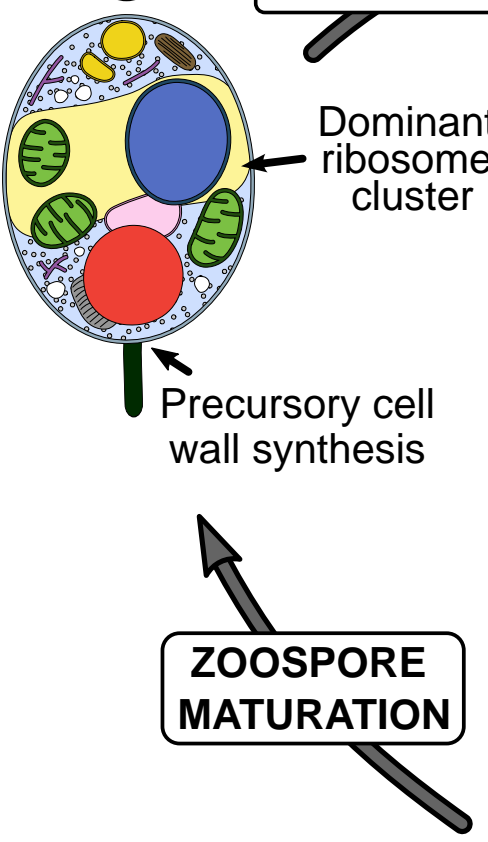

- Glycogen degradation Rumposome enlargement - Ribosome cluster formation

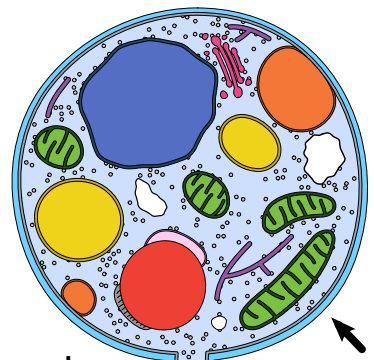

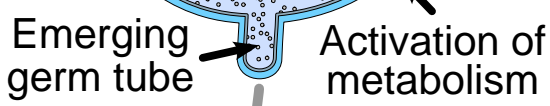

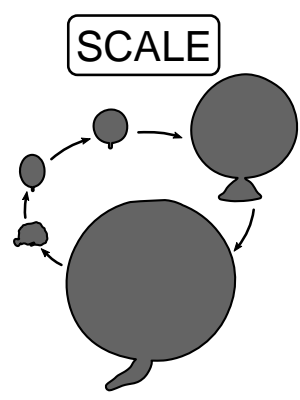

- Glycogen synthesis

- Lipid anabolism

- Apophysis development

(3)

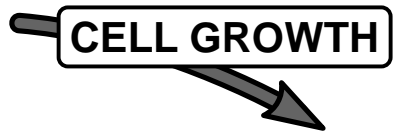

Vacuolarisation

Intravacuolar lipid globules

Chitinous

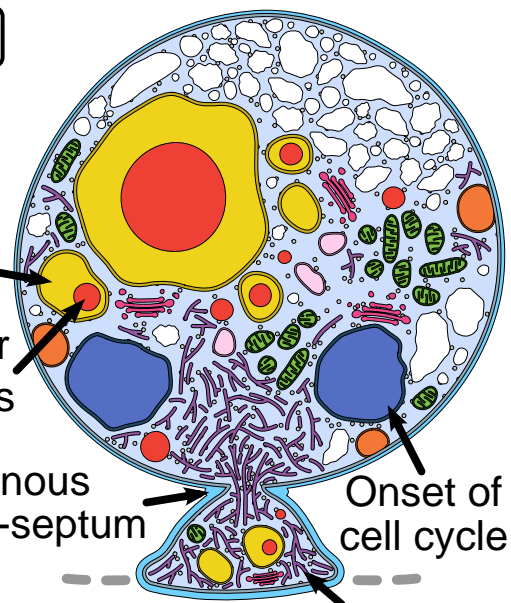

(4) Discharge through apophysis pseudo

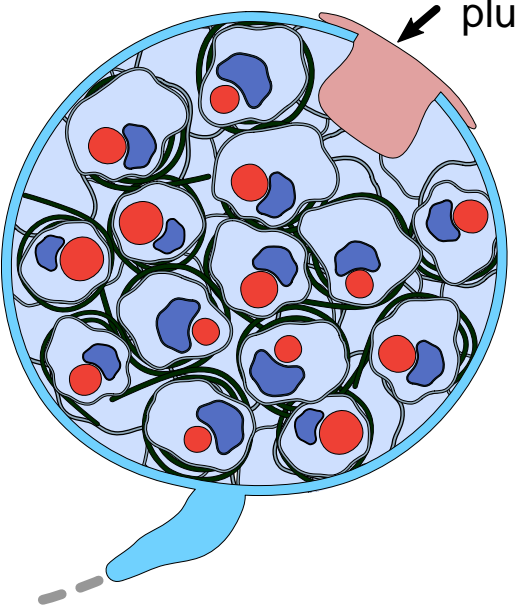

CLEAVAGE

Endocytotic

engulfment

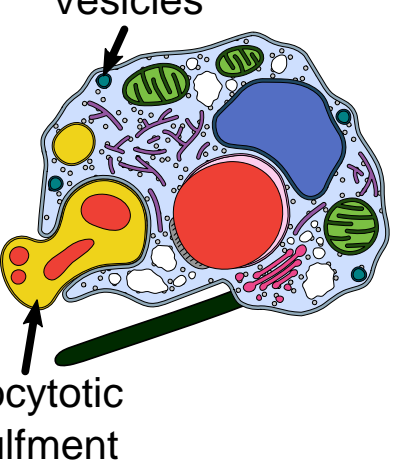

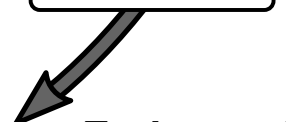

- Endomembrane cleavage -Flagellar biosynthesis

- Discharge pore development 


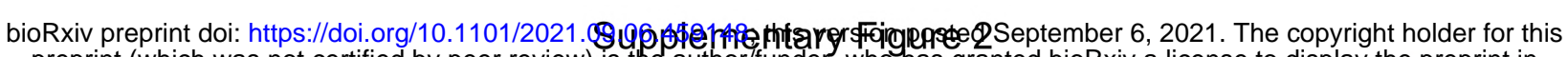

A Zoosporint (which wa perpetuity. It is gade avantable under aCC-BY-NC-ND $/ \mathrm{mm}$ maturneecense. Thallus

Developing
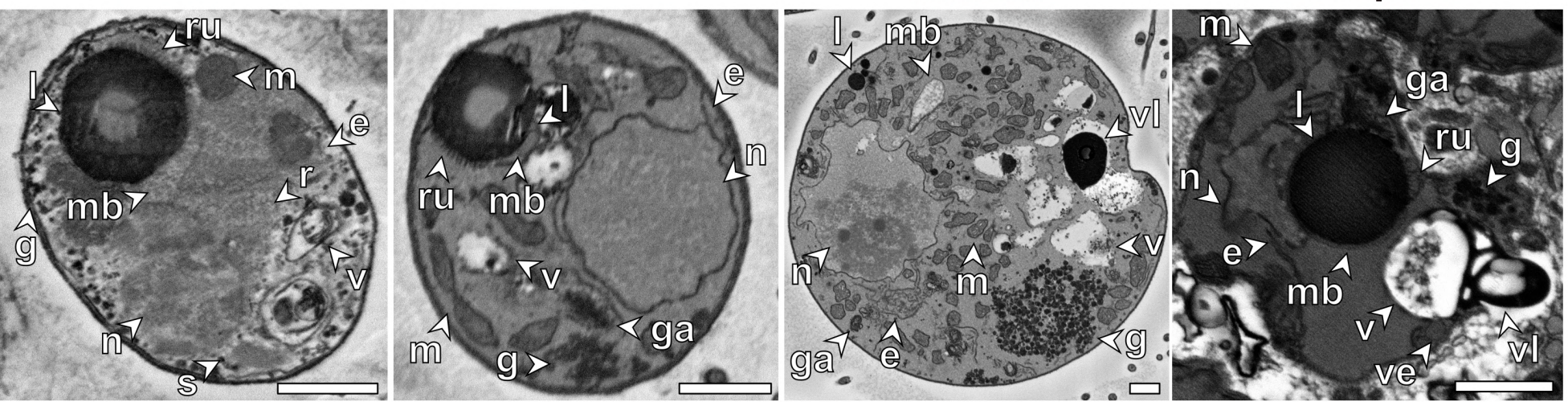

B
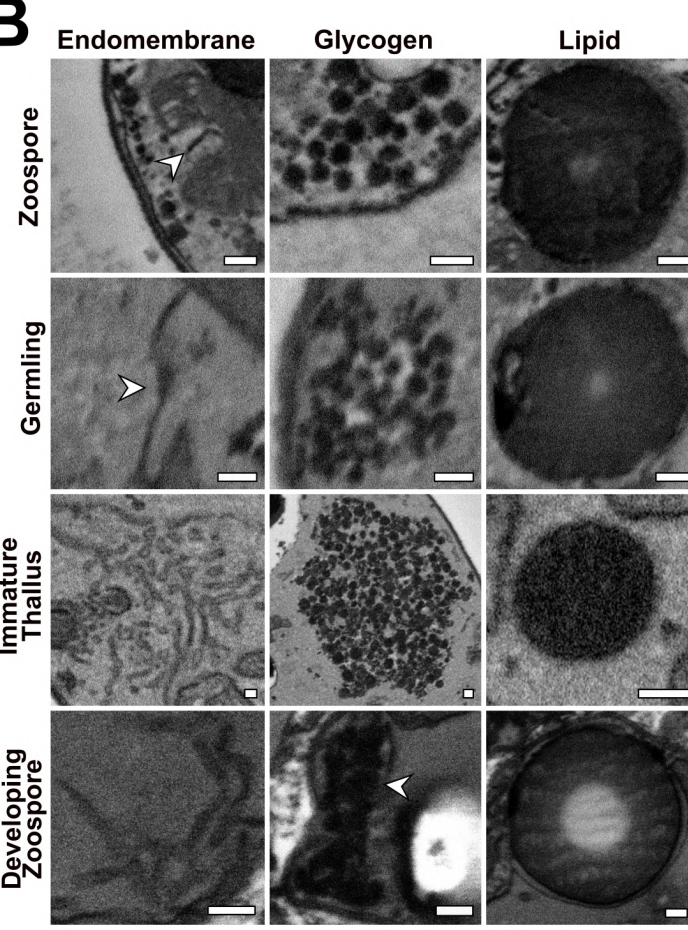

Microbodies

Mitochondria

Nucleus

Vacuole

Golgi Apparatus Peripheral Body

C

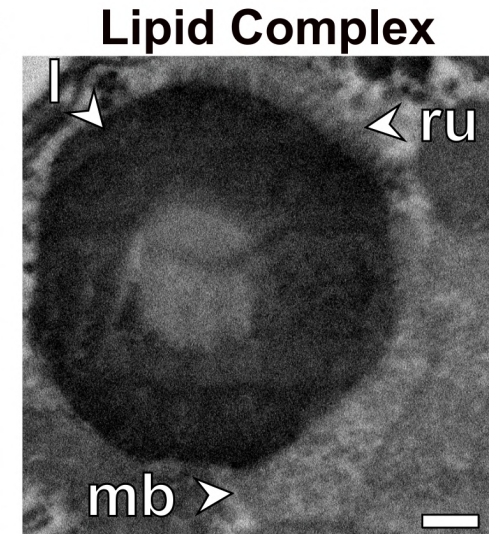

Germling Rhizoid

Striated Inclusion

Ribosome Cluster

Flagellum
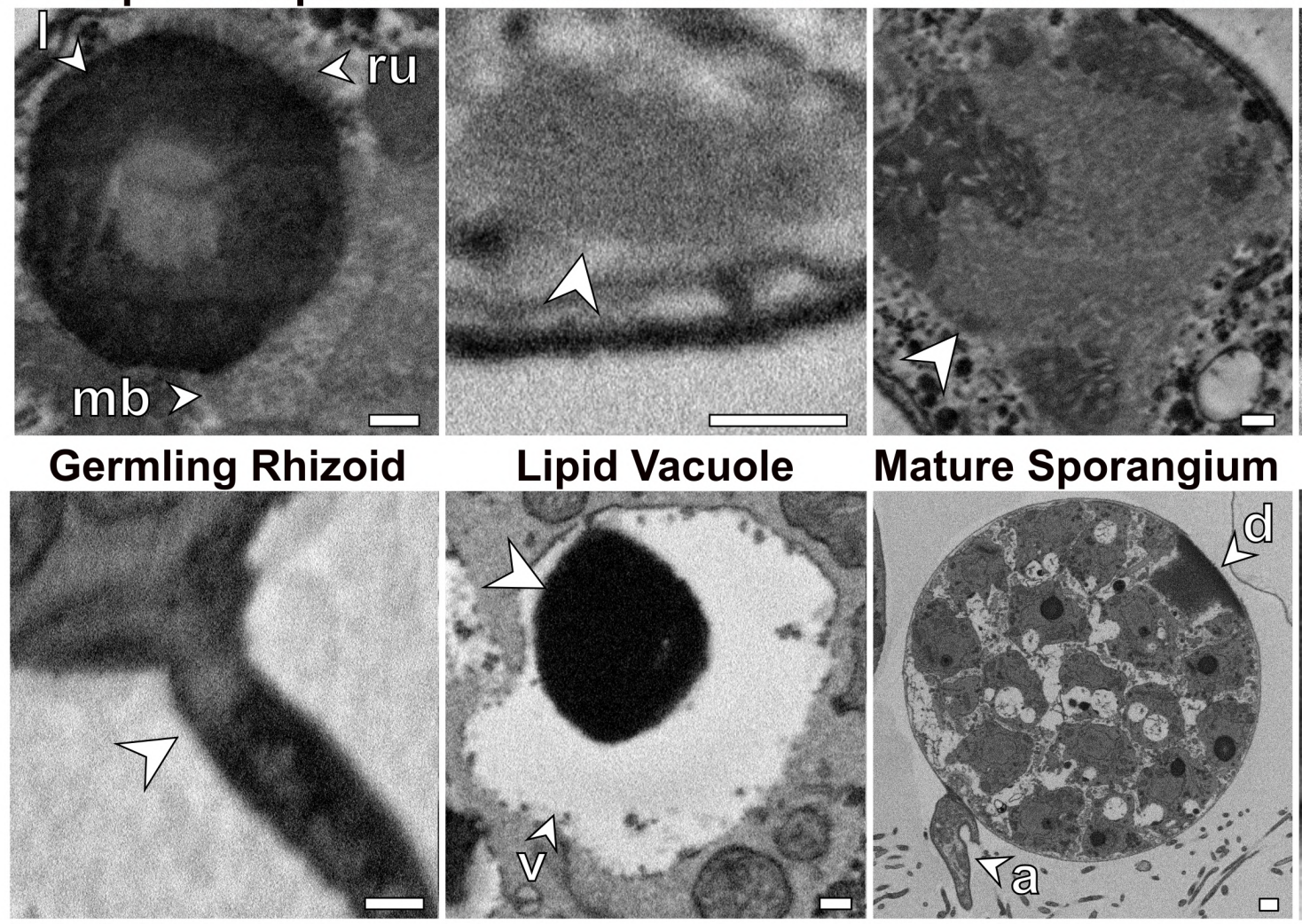

Mature Sporangium

Vesicle

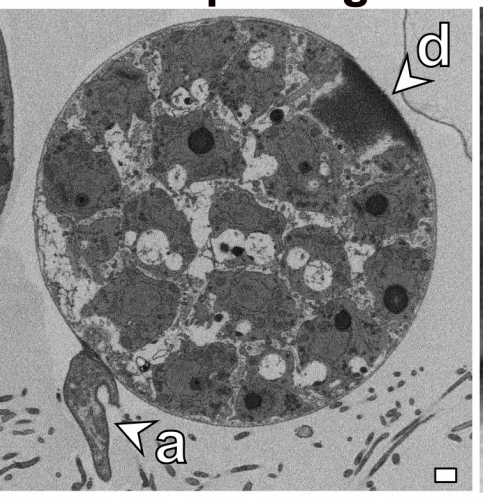


bioRxiv preprint doi: https://doi.org/10.1101/2021. .S.appdemæentavgrsioighblectSeptember 6, 2021. The copyright holder for this preprint (which was not certified by peer review) is the author/20683 boflo has granted bioRxiv a license to display the preprint in
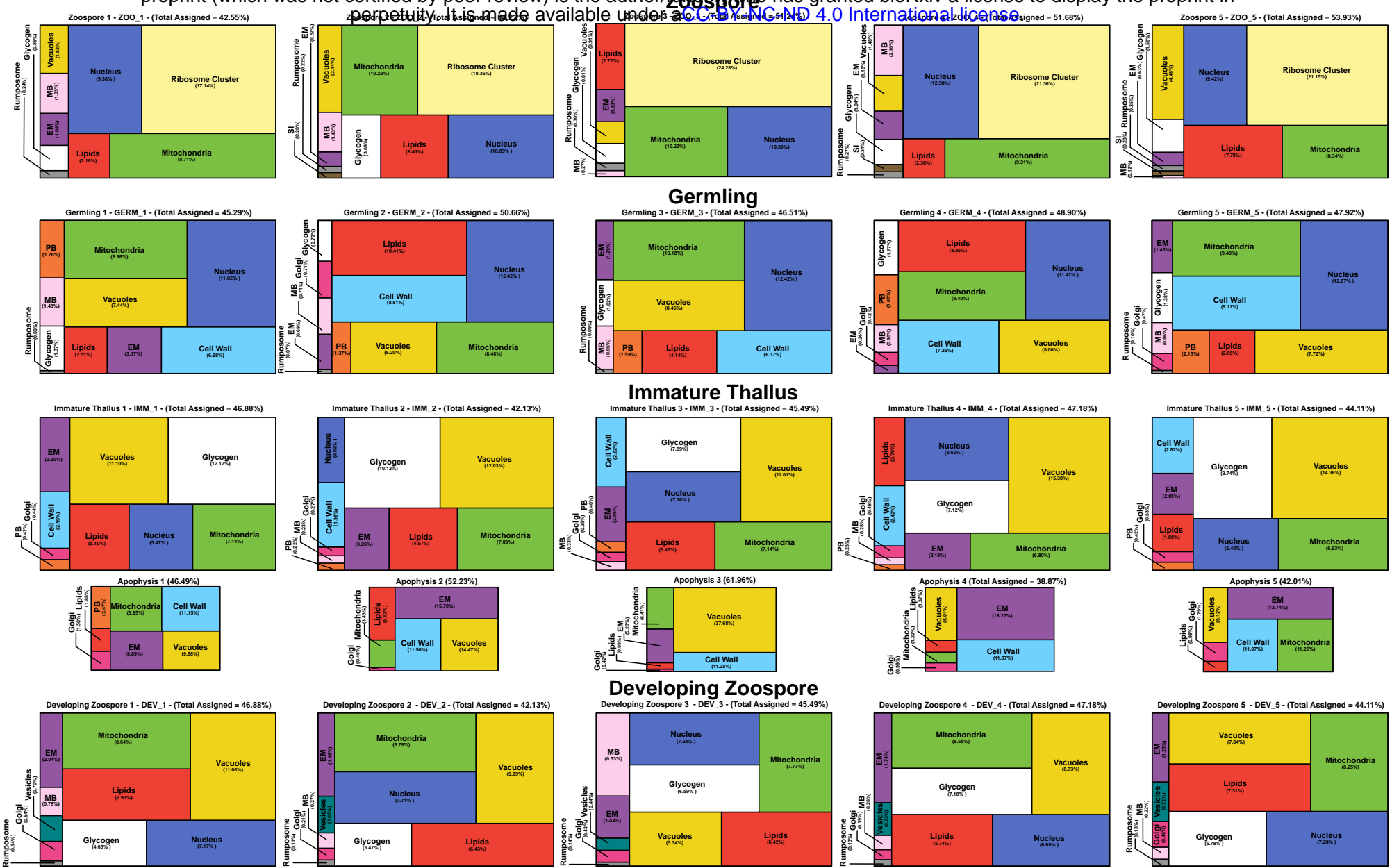

\section{Developing Zoospore}
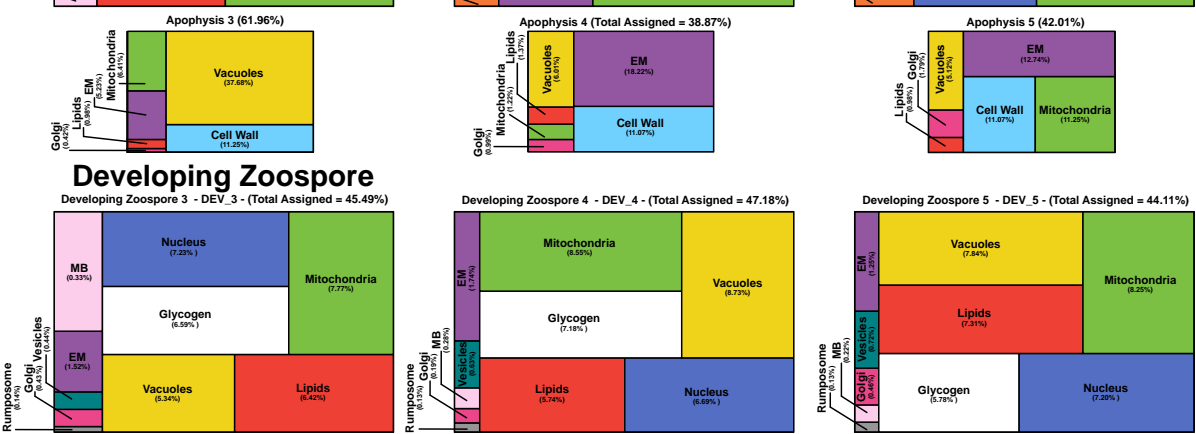


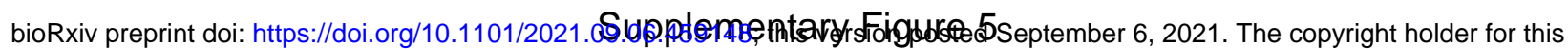
preprint _which was not certified by peer review) is the author/funder, who has granted bioRxiv a license to display the preprint in
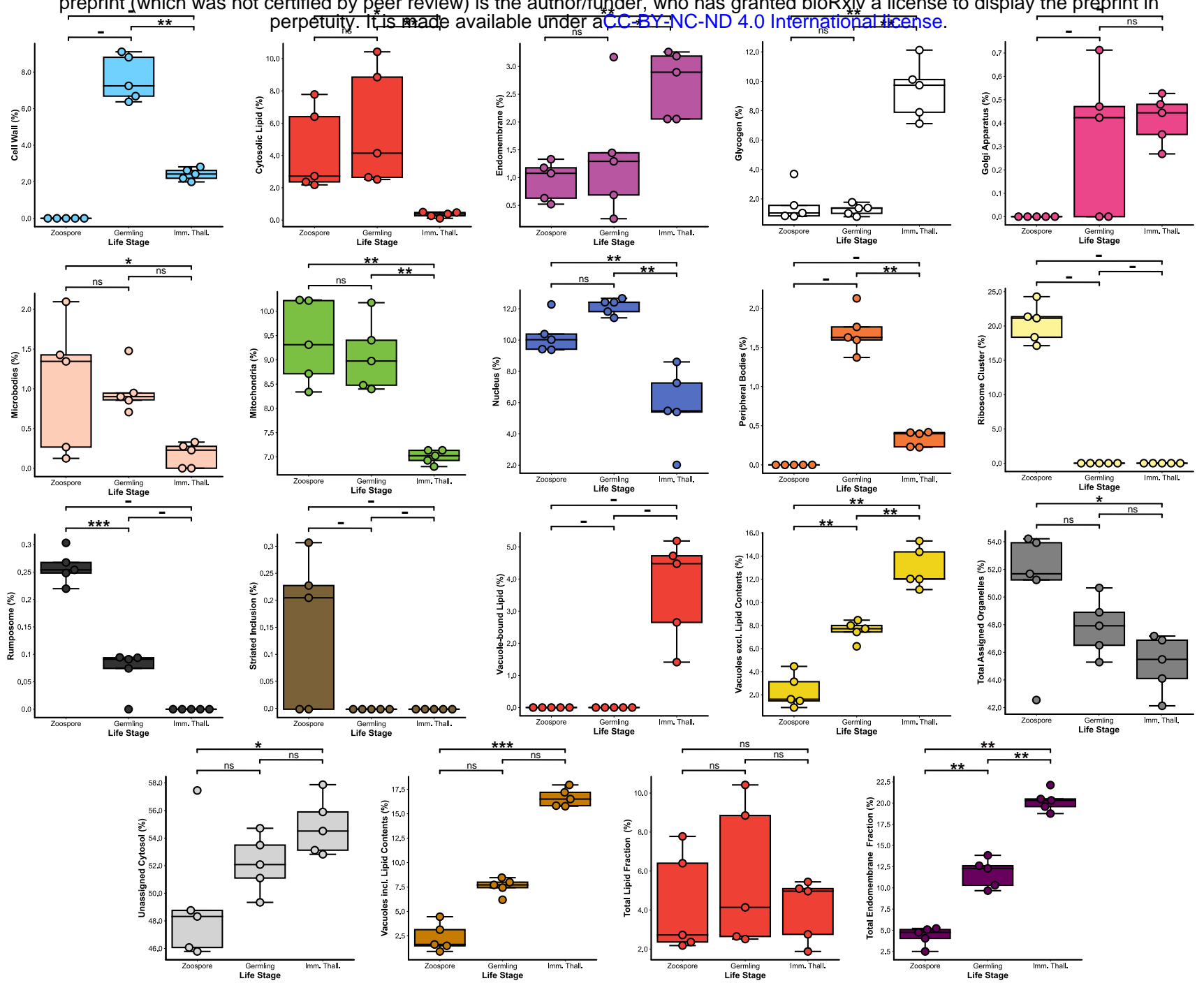


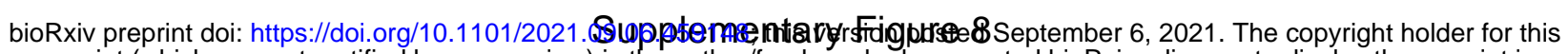

preprint (whish

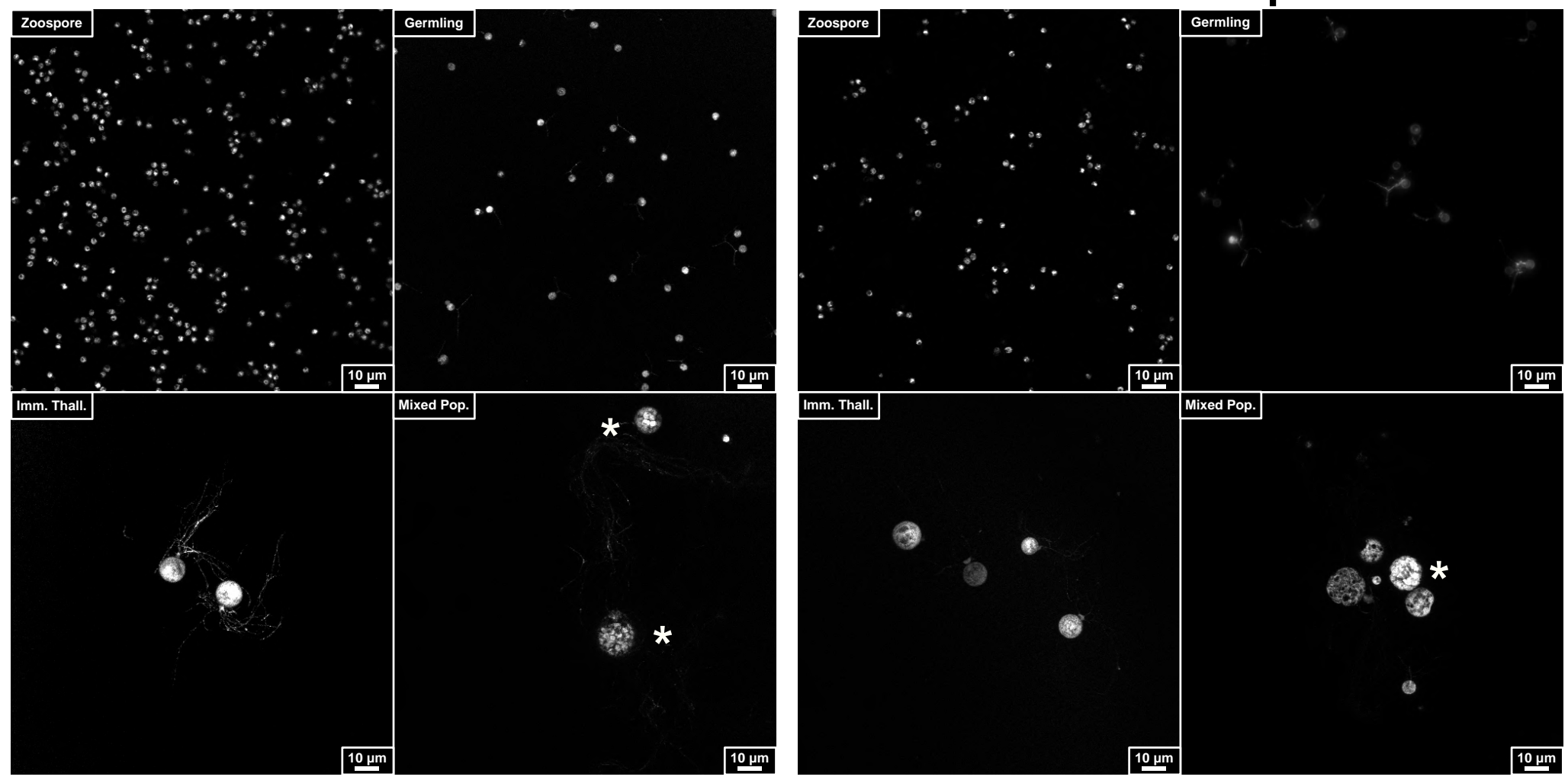




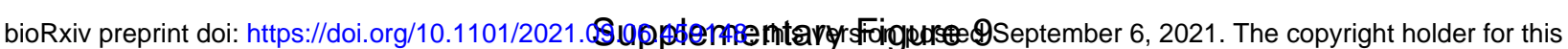
preprint (which was not certified by peer review) is the author/funder, who has granted bioRxiv a license to display the preprint in perpetuity. It is made available under aCC-BY-NC-ND 40 lnternationallicense

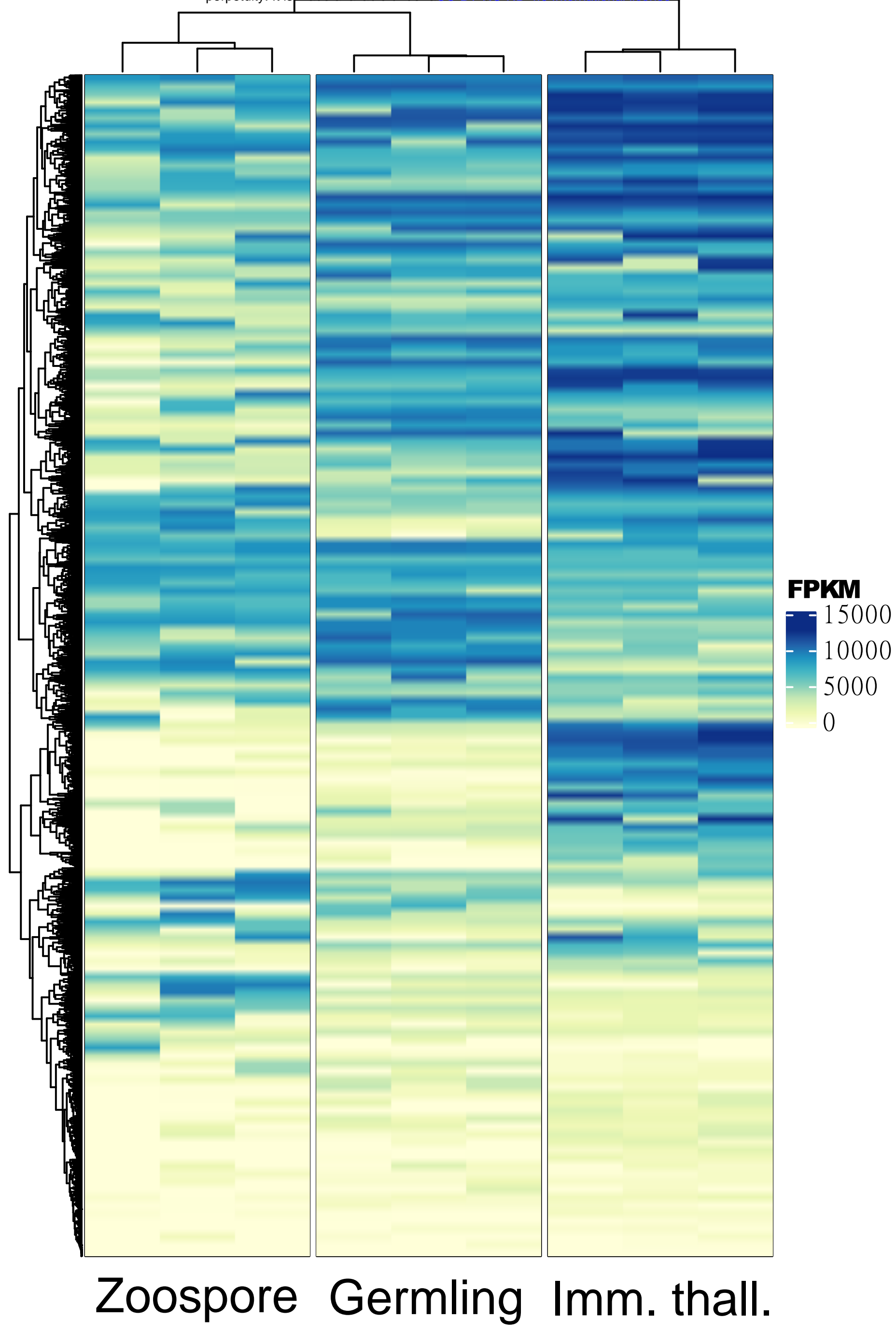




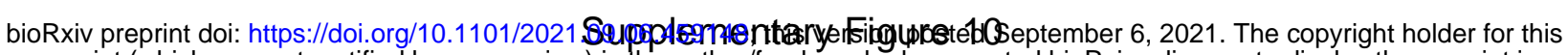
preprint (which was not certified by peer review) is the author/funder, who has granted bioRxiv a license to display the preprint in perpetuity. It is made available under aCC-BY-NC-ND 4.0 International license.
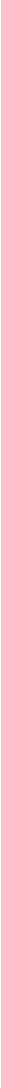


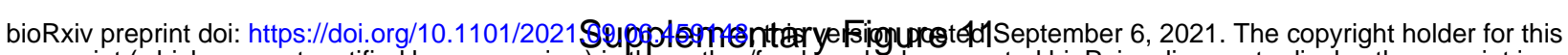

preprint (which was not certified by peer review) is the author/funder, who has granted bioRxiv a license to display the preprint in perpetuity. It is made available under aCC-BY-NC-ND 4.0 International license.

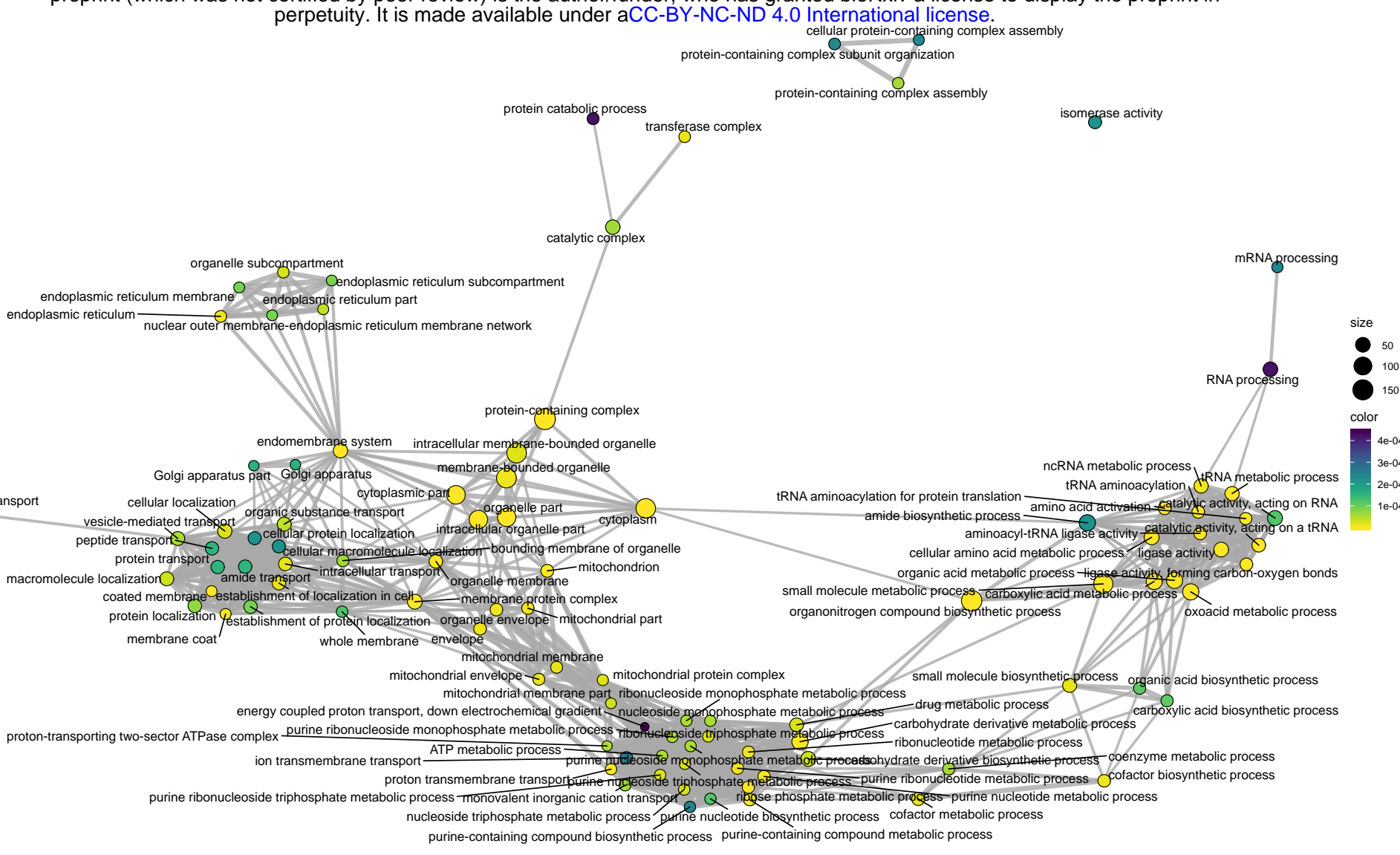




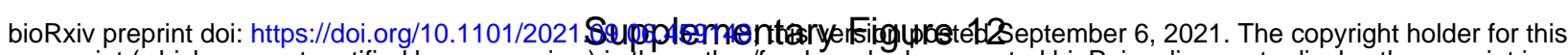
preprint (which was not certified by peer review) is the author/funder, who has granted bioRxiv a license to display the preprint in perpetuity. It is made available under aCC-BY-NC-ND 4.0 International license.

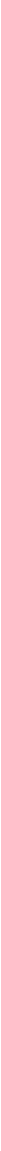




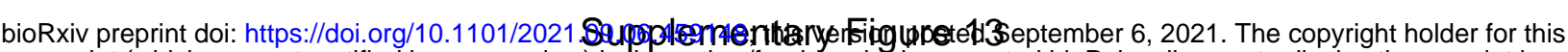
preprint (which was not certified by peer review) is the author/funder, who has granted bioRxiv a license to display the preprint in

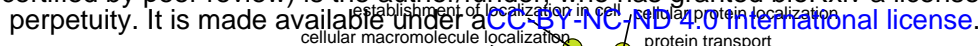

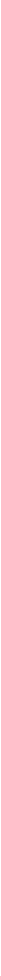

catabolic process ubiquitin-dependent protein catabolic protein catabolic process cellular protein catabolic process hreonine-type endgpeptidase achiety

lytic complex

ynein complex

microtubule cytoskeleton

microtubule-based movement microtubule motor activity movement of cell or subcellular component cytgskeletor
tubulin binding 
Supplementary Table 1. Volumetric quantities of cellular structures recorded across chytrid life stages. Data given to 3 decimal places.

\begin{tabular}{|c|c|c|c|c|c|c|c|c|c|c|}
\hline \multirow{2}{*}{$\begin{array}{l}\text { Cellular } \\
\text { Structure }\end{array}$} & \multicolumn{10}{|c|}{ Chytrid Life stage - Volume in $\mu^{3}{ }^{3}$} \\
\hline & $\begin{array}{c}\text { Zoospore } \\
(n=5)\end{array}$ & $\begin{array}{c} \pm \\
\text { S.D }\end{array}$ & $\begin{array}{l}\text { Germling } \\
(n=5)\end{array}$ & $\begin{array}{c} \pm \\
\text { S.D }\end{array}$ & $\begin{array}{c}\text { Immature } \\
\text { Thallus }(n=5)\end{array}$ & $\begin{array}{c} \pm \\
\text { S.D }\end{array}$ & $\begin{array}{c}\text { Imm. Thall. } \\
\text { Apophysis }(n=5)\end{array}$ & $\begin{array}{c} \pm \\
\text { S.D }\end{array}$ & $\begin{array}{l}\text { Dev. Zoospore } \\
\qquad(n=5)\end{array}$ & $\begin{array}{c} \pm \\
\text { S.D }\end{array}$ \\
\hline Total Volume & 20.749 & 1.687 & 33.991 & 2.042 & 1116.291 & 206.198 & 12.179 & 5.951 & 21.455 & 0.590 \\
\hline Cell Wall & 0.000 & 0.000 & 2.594 & 0.425 & 26.448 & 3.112 & 1.326 & 0.600 & 0.000 & 0.000 \\
\hline Cytosolic Lipid & 0.894 & 0.558 & 1.889 & 1.127 & 3.754 & 1.983 & 0.115 & 0.183 & 1.451 & 0.183 \\
\hline Endomembrane & 0.195 & 0.070 & 0.479 & 0.410 & 30.829 & 11.485 & 1.390 & 0.729 & 0.346 & 0.072 \\
\hline Glycogen & 0.332 & 0.253 & 0.433 & 0.138 & 104.359 & 27.516 & 0.000 & 0.000 & 1.190 & 0.334 \\
\hline Golgi Apparatus & 0.000 & 0.000 & 0.106 & 0.101 & 4.498 & 0.898 & 0.153 & 0.149 & 0.079 & 0.033 \\
\hline Microbodies & 0.226 & 0.189 & 0.336 & 0.118 & 2.025 & 1.857 & 0.000 & 0.000 & 0.194 & 0.253 \\
\hline Mitochondria & 1.937 & 0.170 & 3.092 & 0.347 & 78.194 & 14.392 & 0.977 & 0.934 & 1.803 & 0.113 \\
\hline Nucleus & 2.143 & 0.372 & 4.129 & 0.293 & 63.155 & 30.682 & 0.000 & 0.000 & 1.544 & 0.057 \\
\hline Peripheral Bodies & 0.000 & 0.000 & 0.580 & 0.125 & 3.620 & 0.753 & 0.121 & 0.270 & 0.000 & 0.000 \\
\hline Ribosome Cluster & 4.228 & 0.522 & 0.000 & 0.000 & 0.000 & 0.000 & 0.000 & 0.000 & 0.000 & 0.000 \\
\hline Rumposome & 0.053 & 0.005 & 0.024 & 0.014 & 0.000 & 0.000 & 0.000 & 0.000 & 0.028 & 0.003 \\
\hline Striated Inclusion & 0.032 & 0.031 & 0.000 & 0.000 & 0.000 & 0.000 & 0.000 & 0.000 & 0.000 & 0.000 \\
\hline Vacuole-bound Lipid & 0.000 & 0.000 & 0.000 & 0.000 & 42.568 & 20.506 & 0.132 & 0.090 & 0.000 & 0.000 \\
\hline Vacuoles excl. Lipid Contents & 0.488 & 0.311 & 2.576 & 0.369 & 144.077 & 31.251 & 1.568 & 1.234 & 1.809 & 0.472 \\
\hline Vesicles & 0.000 & 0.000 & 0.000 & 0.000 & 0.000 & 0.000 & 0.000 & 0.000 & 0.135 & 0.024 \\
\hline Total Assigned Organelles & 10.527 & 1.399 & 16.240 & 0.607 & 503.526 & 89.771 & 5.781 & 2.508 & 8.579 & 0.632 \\
\hline Unassigned Cytosol & 10.222 & 1.268 & 17.751 & 1.670 & 612.764 & 122.699 & 6.398 & 3.675 & 12.877 & 0.389 \\
\hline Vacuoles incl. Lipid Contents & 0.488 & 0.341 & 2.576 & 0.369 & 186.645 & 40.006 & 1.700 & 1.240 & 1.809 & 0.472 \\
\hline Total Lipid Fraction * & 0.909 & 0.558 & 1.889 & 1.127 & 46.322 & 21.419 & 0.247 & 0.189 & 1.451 & 0.183 \\
\hline Total Endomembrane Fraction ** & 0.275 & 0.375 & 4.018 & 0.802 & 227.616 & 51.755 & 3.363 & 1.212 & 2.563 & 0.445 \\
\hline
\end{tabular}

*A functional category defined by the sum of cytosolic and vacuole-bound lipids.

${ }^{* *}$ A functional category defined by the sum of the endomembrane, Golgi apparatus, microbodies, peripheral bodies, vacuoles incl. lipid contents, and vesicles. 
Supplementary Table 2. Numerical quantities of cellular structures recorded across chytrid life stages. Data given to 3 decimal places.

\begin{tabular}{|c|c|c|c|c|c|c|c|c|c|c|}
\hline \multirow{2}{*}{$\begin{array}{l}\text { Cellular } \\
\text { Structure }\end{array}$} & \multicolumn{10}{|c|}{ Chytrid Life stage - Volume in $\mu \mathrm{m}^{3}$} \\
\hline & $\begin{array}{c}\text { Zoospore } \\
(n=5)\end{array}$ & $\begin{array}{c} \pm \\
\text { S.D }\end{array}$ & $\begin{array}{c}\text { Germling } \\
(n=5)\end{array}$ & $\begin{array}{c} \pm \\
\text { S.D }\end{array}$ & $\begin{array}{c}\text { Immature } \\
\text { Thallus }(n=5)\end{array}$ & $\begin{array}{c} \pm \\
\text { S.D }\end{array}$ & $\begin{array}{c}\text { Imm. Thall. } \\
\text { Apophysis }(n=5)\end{array}$ & $\begin{array}{c} \pm \\
\text { S.D }\end{array}$ & $\begin{array}{l}\text { Dev. Zoospore } \\
\quad(n=5)\end{array}$ & $\begin{array}{c} \pm \\
\text { S.D }\end{array}$ \\
\hline Total Volume & NA & NA & NA & NA & NA & NA & NA & NA & NA & NA \\
\hline Cell Wall & 0.000 & 0.000 & 1.000 & 0.000 & 1.000 & 0.000 & 1.000 & 0.000 & 0.000 & 0.000 \\
\hline Cytosolic Lipid & 1.000 & 0.000 & 1.000 & 0.000 & 68.800 & 55.233 & 13.600 & 14.276 & 1.000 & 0.000 \\
\hline Endomembrane & 57.000 & 14.782 & 88.800 & 18.336 & 1513.800 & 641.545 & 45.000 & 35.050 & 88.400 & 21.629 \\
\hline Glycogen & 331.200 & 76.424 & 167.800 & 56.193 & 1075.000 & 137.099 & 0.000 & 0.000 & 91.400 & 32.601 \\
\hline Golgi Apparatus & 0.000 & 0.000 & 1.400 & 1.342 & 62.200 & 13.180 & 1.800 & 1.095 & 1.400 & 0.548 \\
\hline Microbodies & 1.400 & 0.548 & 1.400 & 0.548 & 10.800 & 11.692 & 0.000 & 0.000 & 1.200 & 0.447 \\
\hline Mitochondria & 2.800 & 2.490 & 1.200 & 0.447 & 237.200 & 129.820 & 27.600 & 31.198 & 9.000 & 3.082 \\
\hline Nucleus & 1.000 & 0.000 & 1.000 & 0.000 & 1.800 & 1.304 & 0.000 & 0.000 & 1.000 & 0.000 \\
\hline Peripheral Bodies & 0.000 & 0.000 & 3.600 & 2.074 & 52.600 & 23.650 & 1.200 & 2.683 & 0.000 & 0.000 \\
\hline Ribosome Cluster & 1.000 & 0.000 & 0.000 & 0.000 & 0.000 & 0.000 & 0.000 & 0.000 & 0.000 & 0.000 \\
\hline Rumposome & 1.000 & 0.000 & 0.8 & 0.447 & 0.000 & 0.000 & 0.000 & 0.000 & 1.000 & 0.000 \\
\hline Striated Inclusion & 0.600 & 0.548 & 0.000 & 0.000 & 0.000 & 0.000 & 0.000 & 0.000 & 0.000 & 0.000 \\
\hline Vacuole-bound Lipid & 0.000 & 0.000 & 0.000 & 0.000 & 70.600 & 39.835 & 4.400 & 2.074 & 0.000 & 0.000 \\
\hline Vacuoles excl. Lipid Contents & 8.000 & 1.581 & 4.200 & 3.271 & 69.800 & 37.164 & 19.800 & 14.856 & 12.200 & 9.497 \\
\hline Vesicles & 0.000 & 0.000 & 0.000 & 0.000 & 0.000 & 0.000 & 0.000 & 0.000 & 53.600 & 8.905 \\
\hline Total Assigned Organelles & 405.000 & 81.557 & 272.200 & 59.302 & 3163.600 & 756.752 & 114.400 & 62.408 & 260.200 & 48.561 \\
\hline Unassigned Cytosol & NA & NA & NA & NA & NA & NA & NA & NA & NA & NA \\
\hline Vacuoles incl. Lipid Contents & 8.000 & 1.581 & 4.200 & 3.271 & 69.800 & 37.164 & 19.800 & 14.856 & 12.200 & 9.497 \\
\hline Total Lipid Fraction $*$ & 1.000 & 0.000 & 1.000 & 0.000 & 139.400 & 60.789 & 18.000 & 15.922 & 1.000 & 0.000 \\
\hline Total Endomembrane Fraction $* *$ & 75.400 & 19.424 & 99.400 & 19.501 & 1709.200 & 617.922 & 67.800 & 43.540 & 156.800 & 22.797 \\
\hline
\end{tabular}

*A functional category defined by the sum of cytosolic and vacuole-bound lipids.

${ }^{* *}$ A functional category defined by the sum of the endomembrane, Golgi apparatus, microbodies, peripheral bodies, vacuoles incl. lipid contents, and vesicles. 
Supplementary Table 3. Volumetric percentages and statistical comparisons of cellular structures recorded across chytrid life stages. Data given to 3 decimal places.

\begin{tabular}{|c|c|c|c|c|c|c|c|c|c|}
\hline \multirow{2}{*}{$\begin{array}{c}\text { Cellular } \\
\text { Structure }\end{array}$} & \multicolumn{9}{|c|}{ Chytrid Life stage - Volumetric \% } \\
\hline & $\begin{array}{c}\text { Zoospore } \\
(n=5)\end{array}$ & $\begin{array}{c} \pm \\
\text { S.D }\end{array}$ & $\begin{array}{c}\text { Germling } \\
(n=5)\end{array}$ & $\begin{array}{c} \pm \\
\text { S.D }\end{array}$ & $\begin{array}{c}\text { Immature } \\
\text { Thallus }(n=5)\end{array}$ & $\begin{array}{c} \pm \\
\text { S.D }\end{array}$ & Statistical Test used & $p$-Value & $\begin{array}{c}\text { Posthoc } \\
\text { Annotation }\end{array}$ \\
\hline Total Volume & 100.000 & 0 & 100.000 & 0 & 100.000 & 0.000 & NA & NA & NA \\
\hline Cell Wall & 0.000 & 0.000 & 7.644 & 1.245 & 2.409 & 0.328 & Mann Whitney U & $<0.01$ & $A B C$ \\
\hline Cytosolic Lipid & 4.290 & 2.610 & 5.714 & 3.678 & 0.341 & 0.159 & Kruskal & $<0.01$ & $A A B$ \\
\hline Endomembrane & 0.948 & 0.353 & 1.371 & 1.112 & 2.691 & 0.597 & ANOVA & $<0.01$ & $A A B$ \\
\hline Glycogen & 1.590 & 1.213 & 1.265 & 0.376 & 9.399 & 1.969 & Kruskal & $<0.01$ & $A A B$ \\
\hline Golgi Apparatus & 0.000 & 0.000 & 0.321 & 0.313 & 0.414 & 0.104 & Mann Whitney U & $>0.05$ & $A B B$ \\
\hline Microbodies & 1.052 & 0.836 & 0.978 & 0.293 & 0.167 & 0.156 & ANOVA & $<0.05$ & $A A B B$ \\
\hline Mitochondria & 9.363 & 0.861 & 9.086 & 0.732 & 7.005 & 0.143 & ANOVA & $<0.001$ & $A A B$ \\
\hline Nucleus & 10.297 & 1.187 & 12.151 & 0.512 & 5.749 & 2.477 & ANOVA & $<0.001$ & $A A B$ \\
\hline Peripheral Bodies & 0.000 & 0.000 & 1.696 & 0.278 & 0.336 & 0.100 & Mann Whitney U & $<0.01$ & $A B C$ \\
\hline Ribosome Cluster & 20.457 & 2.798 & 0.000 & 0.000 & 0.000 & 0.000 & NA & NA & $A B B$ \\
\hline Rumposome & 0.258 & 0.030 & 0.095 & 0.071 & 0.000 & 0.000 & T-Test & $<0.001$ & $A B C$ \\
\hline Striated Inclusion & 0.147 & 0.139 & 0.000 & 0.000 & 0.000 & 0.000 & NA & NA & $A B B$ \\
\hline Vacuole-bound Lipid & 0.000 & 0.000 & 0.000 & 0.000 & 3.689 & 1.596 & NA & NA & $A A B$ \\
\hline Vacuoles excl. Lipid Contents & 2.322 & 1.453 & 7.560 & 0.852 & 12.958 & 1.780 & ANOVA & $<0.001$ & $A B C$ \\
\hline Total Assigned Organelles & 50.724 & 4.754 & 47.857 & 2.082 & 45.159 & 2.087 & ANOVA & $>0.05$ & $A A B B$ \\
\hline Unassigned Cytosol & 49.276 & 4.754 & 52.143 & 2.082 & 54.841 & 2.087 & ANOVA & $<0.05$ & $A A B B$ \\
\hline Vacuoles incl. Lipid Contents & 2.322 & 1.453 & 7.560 & 0.852 & 16.647 & 0.930 & Kruskal & $<0.01$ & $A A B$ \\
\hline Total Lipid Fraction $*$ & 4.290 & 2.610 & 5.714 & 3.678 & 4.030 & 1.604 & Kruskal & $>0.05$ & $A A A$ \\
\hline Total Endomembrane Fraction ** & 4.322 & 1.113 & 11.745 & 1.719 & 20.255 & 1.248 & ANOVA & $<0.001$ & $A B C$ \\
\hline
\end{tabular}

*A functional category defined by the sum of cytosolic and vacuole-bound lipids.

**A functional category defined by the sum of the endomembrane, Golgi apparatus, microbodies, peripheral bodies, vacuoles incl. lipid contents, and vesicles. 
Supplementary Table 4. Volumetric percentages and statistical comparisons of cell bodies and their corresponding apophyses in immature thalli. Data given to 3 decimal places.

\begin{tabular}{|c|c|c|c|c|c|c|}
\hline \multirow{2}{*}{$\begin{array}{l}\text { Cellular } \\
\text { Structure }\end{array}$} & \multicolumn{6}{|c|}{ Cellular Structure - Volumetric \% } \\
\hline & $\begin{array}{c}\text { Cell Body } \\
(n=5)\end{array}$ & $\begin{array}{c} \pm \\
\text { S.D }\end{array}$ & $\begin{array}{c}\text { Apophysis } \\
(n=5)\end{array}$ & $\begin{array}{c} \pm \\
\text { S.D }\end{array}$ & Statistical Test used & $p$-Value \\
\hline Total Volume & 100.000 & 0.000 & 100.000 & 0.000 & NA & NA \\
\hline Cell Wall & 2.409 & 0.328 & 11.034 & 0.534 & Mann Whitney U & $<0.01$ \\
\hline Cytosolic Lipid & 0.341 & 0.159 & 1.308 & 2.318 & Mann Whitney U & $>0.05$ \\
\hline Endomembrane & 2.691 & 0.597 & 12.155 & 5.202 & Mann Whitney U & $<0.01$ \\
\hline Glycogen & 9.399 & 1.969 & 0.000 & 0.000 & NA & NA \\
\hline Golgi Apparatus & 0.414 & 0.104 & 1.047 & 0.627 & Mann Whitney U & $>0.05$ \\
\hline Microbodies & 0.167 & 0.156 & 0.000 & 0.000 & NA & NA \\
\hline Mitochondria & 7.005 & 0.143 & 6.429 & 4.215 & Mann Whitney U & $>0.05$ \\
\hline Nucleus & 5.749 & 2.477 & 0.000 & 0.000 & NA & NA \\
\hline Peripheral Bodies & 0.336 & 0.100 & 0.693 & 1.551 & Mann Whitney U & $>0.05$ \\
\hline Vacuole-bound Lipid & 3.689 & 1.596 & 1.056 & 0.350 & Mann Whitney U & $<0.05$ \\
\hline Vacuoles excl. Lipid Contents & 12.958 & 1.780 & 14.589 & 13.420 & Mann Whitney U & $>0.05$ \\
\hline Total Assigned Organelles & 45.159 & 2.087 & 48.312 & 9.136 & Paired T-Test & $>0.05$ \\
\hline Unassigned Cytosol & 54.841 & 2.087 & 51.688 & 9.136 & Paired T-Test & $>0.05$ \\
\hline Vacuoles incl. Lipid Contents & 16.647 & 0.930 & 15.645 & 13.371 & Mann Whitney U & $>0.05$ \\
\hline Total Lipid Fraction $*$ & 4.030 & 1.604 & 2.364 & 2.407 & Paired T-Test & $>0.05$ \\
\hline Total Endomembrane Fraction ** & 20.255 & 1.248 & 29.542 & 9.135 & Mann Whitney U & $<0.05$ \\
\hline
\end{tabular}

*A functional category defined by the sum of cytosolic and vacuole-bound lipids.

${ }^{* *}$ A functional category defined by the sum of the endomembrane, Golgi apparatus, microbodies, peripheral bodies, vacuoles incl. lipid contents, and vesicles. 
Supplementary Table 5. Volumetric percentages and statistical comparisons of free-swimming and developing zoospores. Data given to 3 decimal places.

\begin{tabular}{|c|c|c|c|c|c|c|}
\hline \multirow{2}{*}{$\begin{array}{l}\text { Cellular } \\
\text { Structure }\end{array}$} & \multicolumn{6}{|c|}{ Chytrid Life stage - Volumetric \% } \\
\hline & $\begin{array}{l}\text { Mature Zoospore } \\
\quad(n=5)\end{array}$ & $\begin{array}{c} \pm \\
\text { S.D }\end{array}$ & $\begin{array}{l}\text { Developing Zoospore } \\
\qquad(n=5)\end{array}$ & $\begin{array}{c} \pm \\
\text { S.D }\end{array}$ & Statistical Test used & $p$-Value \\
\hline Total Volume & 100.000 & 0.00 & 100.000 & 100.000 & NA & NA \\
\hline Cytosolic Lipid & 4.290 & 2.610 & 6.766 & 0.859 & Mann Whitney U & $>0.05$ \\
\hline Endomembrane & 0.948 & 0.353 & 1.607 & 0.296 & T-Test & $<0.05$ \\
\hline Glycogen & 1.590 & 1.213 & 5.536 & 1.494 & T-Test & $<0.01$ \\
\hline Golgi Apparatus & 0.000 & 0.000 & 0.367 & 0.156 & NA & NA \\
\hline Microbodies & 1.052 & 0.836 & 0.909 & 1.191 & Mann Whitney U & $>0.05$ \\
\hline Mitochondria & 9.363 & 0.861 & 8.400 & 0.403 & T-Test & $>0.05$ \\
\hline Nucleus & 10.297 & 1.187 & 7.202 & 0.361 & T-Test & $<0.001$ \\
\hline Ribosome Cluster & 20.457 & 2.798 & 0.000 & 0.000 & NA & NA \\
\hline Rumpsome & 0.258 & 0.030 & 0.129 & 0.013 & T-Test & $<0.001$ \\
\hline Striated Inclusion & 0.147 & 0.139 & 0.000 & 0.000 & NA & NA \\
\hline Vacuoles & 2.322 & 1.453 & 8.410 & 2.082 & T-Test & $<0.001$ \\
\hline Vesicles & 0.000 & 0.000 & 0.630 & 0.113 & NA & NA \\
\hline Total Assigned Organelles & 50.724 & 4.754 & 39.956 & 2.145 & Mann Whitney U & $<0.05$ \\
\hline Unassigned Cytosol & 49.276 & 4.754 & 60.044 & 2.145 & Mann Whitney U & $<0.05$ \\
\hline Total Endomembrane Fraction $* *$ & 4.322 & 1.113 & 11.923 & 1.856 & T-Test & $<0.001$ \\
\hline
\end{tabular}

${ }^{* *}$ A functional category defined by the sum of the endomembrane, Golgi apparatus, microbodies, peripheral bodies, vacuoles incl. lipid contents, and vesicles. 